\title{
Selection and validation of a complex fishery model using an uncertainty hierarchy
}

\author{
Sigrid Lehuta ${ }^{a, *}$, Pierre Petitgas ${ }^{a}$, Stéphanie Mahévas ${ }^{a}$, Martin Huret $^{b}$, Youen Vermard ${ }^{c}$, \\ Andrés Uriarte $^{\mathrm{d}}$, Nicholas R. Record ${ }^{\mathrm{e}}$
}

\author{
a IFREMER, rue de l'île d'Yeu BP 21105, 44311 Nantes Cedex 03, France \\ b IFREMER, Centre de Brest, B.P. 70, 29280 Plouzané, France \\ c IFREMER, 150 quai Gambetta, B.P. 699, 62321 Boulogne/Mer Cedex, France \\ d AZTI tecnalia, Herrera Kaia-Portualdea z/g E20110, Guipuzcoa, Spain \\ ${ }^{\mathrm{e}}$ Earth \& Oceanographic Science Department, Bowdoin College, Brunswick, ME 04011, USA \\ *: Corresponding author : Sigrid Lehuta, Tel.: +33 321995061 ; email address : sigridlehuta@gmail.com
}

\begin{abstract}
:
Assessing the validity of a model is essential for its credibility especially when the model is used as decision making tool. Complex dynamic fishery models are recommended to investigate the functioning of fisheries and to assess the impact of management strategies, particularly spatial fishing regulations. However, their use is limited due to the difficulty and computational cost of parameterizing and gaining confidence, particularly for parameter rich models. These difficulties are compounded by uncertainty regarding parameter values, many of which are often taken from literature or estimated indirectly. Here we propose a methodology to improve confidence and understanding in the model, easily transferable to any complex model. The approach combines sensitivity analysis, scalability of parameters, optimization procedures, and model skill assessment in order to parameterize, validate and achieve the most plausible formulation of a model given the available knowledge while reducing the computational load. The methodology relies on five steps: (1) sensitivity analysis, (2) classification of parameters into a hierarchy according to their sensitivity and the nature of their uncertainty, (3) building of alternative formulations, (4) calibration and (5) skill evaluation. The approach is illustrated here by reviewing the parameterization of the ISIS-Fish model of the anchovy fishery in the Bay of Biscay. By using this approach, it is possible to make a thorough assessment of lacking information (e.g. accessibility to fishing and adult mortality) and to identify the strengths and weaknesses of the model in the context of different hypotheses. When applied to the ISIS-Fish model, the results suggest higher egg and adult mortality than formerly estimated, as well as new estimates for the migration towards spawning areas. They show the reliability of the model in terms of correlations with observations and the need for further efforts to model purse seiner catches. The methodology proved to be a cost-efficient tool for objectively assessing applied model validity in cases where parameter values are a mix of literature, expert opinion and calibration.
\end{abstract}




\section{Highlights}

A five-step methodology is proposed to parameterize and validate a complex fishery model. $\longrightarrow$ It combines scalability of parameters, optimization procedure and model skill assessment. $\rightarrow$ It is used to review the ISIS-Fish model of the anchovy fishery in the Bay of Biscay. It modifies our understanding of anchovy dynamics and evidences model strengths and weaknesses.

Keywords: Bay of Biscay anchovy ; Dynamic fishery model ; Model selection ; Uncertainty ; Validation

\section{Introduction}

Assessing the validity of a model is essential for its credibility especially when the model is used as decision making tool (Stow et al., 2009). Although crucial, validation is a non-trivial exercise, which, when attempted, is often qualitative and largely subjective (Allen et al., 2007). In fishery science, models have emerged as the most widely used tools to support management decisions. However, in fishery models, the modelling process is complicated by (1) substantial observational uncertainty and (2) limited data. Observations are often indirectly 
obtained, and there is confusion between measurement error and intrinsic variability, also called process error, which arises from unpredictable natural variability (Charles, 1998; Punt \& Donovan, 2007). Short time series and limited data hardly allow for full understanding of all the mechanisms involved. These limitations can significantly confound validation efforts. In most cases, parameterization is achieved using optimization procedures, which tune parameters and ensure the best fit of the model outputs to the available historical data (Drouineau et al., 2010; Pech et al., 2001). However, such procedures have a number of pitfalls. In many cases, the optimization procedure requires the use of every available time series, and an independent validation cannot be carried out, often leading to confusion between validation and calibration. With the evolution of management strategies, which now include spatial regulations and/or combination of management rules, models have become more complex, for example in terms of time resolution, explicit representation of space, or number of processes described (Pelletier and Mahévas, 2005). The number of parameters, computation time, difficulty to build a likelihood function, or likely confounding effects make simultaneous optimization of all parameters often unfeasible, and parameters must be assessed independently, using available knowledge and integrating this information in the model (Fulton et al., 2004; Kraus et al., 2009; Lehuta et al., 2010; Travers et al., 2006). In these cases, consistency between the parameters of the model has to be verified through rigorous validation.

Given the large uncertainty in parameter values (either due to measurement error when parameters are directly measured, estimation error due to incorrect estimation method and imperfect data, intrinsic variability, or multiple sources of information), but also in model structure (for instance from various interpretations of a mechanism), it is likely that the modeling process will result in a multitude of equally plausible formulations (here used to refer to specification and parameter estimates) of the model, as opposed to a single, 
unambiguously optimal formulation. Moreover, the optimal formulation and the validity of the model depend on the criteria used to assess them, and those criteria are thus crucial (Allen et al., 2007). To accommodate the fact that there cannot be an absolute, nor objective or single test of validity of a model (Sterman, 1984), several authors have promoted the use of specific metrics that reflect various aspects of model skill (correlation, efficiency, accuracy) and have provided more quantitative elements for model evaluation (Jolliff et al., 2009). Additionally, multivariate validation using several output variables at different scales is recommended to demonstrate the appropriateness of model structure (Allen and Somerfield, 2009; Cury et al., 2008; Wiegand et al., 2004).

Given the broad uncertainty and the likely ambiguity of model optimality, it is important to consider alternative model formulations. Consequently, selecting and gaining confidence in the model parameterization are inseparable processes, and they require an iterative process of formulation, parameterization and validation (Wiegand et al., 2003). We propose a methodology that relies on an uncertainty hierarchy to build alternative parameterizations of a model. The methodology then uses several validation criteria and several historical variables to compare their validity. This approach allows us to efficiently and thoroughly explore and assess the space of alternative model formulations and select the most appropriate for a given model purpose.

We applied this approach to the ISIS-Fish model of the anchovy fishery in the Bay of Biscay (Pelletier et al, 2009; Lehuta et al. 2010). It is an example of a deterministic complex fishery model that was developed to evaluate spatial management strategies for anchovy (Lehuta et al. 2010). It was not possible to parameterize the model through an integrated optimization procedure because of the high number of parameters (about 700), the discrete nature of some uncertainty domains and the long duration of simulations (10 minutes for 10 years). We 
propose to review the modelling of this fishery using our methodology to improve model

101 adequacy and credibility.

The Methods section describes the generic approach proposed - that is, to organize

103 parameters in a hierarchy and to rationalize the building of alternative formulations. The

104 Materials section presents the model under study. The Results section presents the application

105 of this methodology to the ISIS-Fish model of the Anchovy fishery in the Bay of Biscay. We

106 detail the classification of parameters in categories; investigate the quality of the calibration,

107 compare the validity of the formulations and assess the influence of time varying parameters.

108 We then discuss the approach and its limits and provide recommendations for applying it

109 more generally.

111 2. Methods

112 The methodology is designed to guide the modeler in the determination of parameter values,

113 in building multiple formulations of the model, and in evaluating and comparing their

114 respective skill.

\subsection{Parameter assessment and alternative formulations}

117 Building a parameterization begins with a review of knowledge on modeled processes and

118 confidence in the model's parameters. Parameters are classified within a hierarchy according

119 to the nature of their uncertainty and their effect on model sensitivity. The first step is a

120 sensitivity analysis, to identify the parameters that significantly influence model results. It is

121 typically a small proportion of the parameters, as evidenced by Lehuta et al. (2010) and stated

122 by Saltelli et al. (2000), which considerably reduces the number of parameters to investigate.

123 Sensitivity analyses are carried out by changing values of input parameters according to a

124 simulation design and analysing the impact on model output using statistical methods. Many 
sensitivity analysis methods exist and the appropriate method must be selected based on the

126 objectives of the analysis, the costs of model runs, the number of parameters and the nature of

127 their uncertainty domains (see Saltelli et al., 2000 for a review of sensitivity analysis

128 methods). The second step is to characterize the uncertainty range for each sensitive

129 parameter. Some parameters have well-known values, unambiguously described in literature.

130 Others parameters are accompanied by various forms of uncertainty, which we divided into

131 three categories. The first encompasses parameters linked to processes that vary in time, and

132 the mechanisms underlying the variability are unknown and thus not modelled. Since our

133 model is deterministic, inter-annual variability cannot be taken into account in prediction

134 through random parameter values and it must be decided whether a fixed value is appropriate

135 or if scenarios must be tested. The second category describes parameters inconsistently

136 estimated, for which several values are available in literature. This happens when various

137 procedures or measuring tools have led to inconsistent estimations or when values obtained in

138 other regions are used to estimate an unknown parameter. The third includes parameters

139 inaccurately estimated or unknown because the assessment methods or data are lacking

140 (Figure 1).

141

These steps taken together produce five categories of parameters, and each category

143 requires a different treatment. Category (i) parameters are those to which the model is not

144 sensitive, and any available value is sufficient. Category (ii) parameters are those with highly

145 certain values, and here again the values are not questioned. Category (iii) parameters have

146 values that are variable in time. As a first step, we propose to consider these as forcing

147 variables in hind-cast simulations. This allows us to evaluate whether an average value is

148 appropriate in prediction or whether time-varying values are necessary. Category (iv)

149 parameters are those for which discrete alternative values are identified in literature. 
150 Calibration could be a solution to decide on the most appropriate value. However here, the

151 interval on which the parameters are defined is discrete rather than continuous, a situation not

152 handled well by optimization algorithms (Nocedal and Wright, 2006). As an alternative to

153 calibration, we propose to build alternative formulations of the model using all the possible

154 values for category (iv) parameters and combining them systematically. The formulations

155 could later be compared to identify the best combination. This constitutes the third step.

156 Finally, sensitive parameters whose values are unknown (category v) have to be estimated

157 using an optimization procedure; this is step four. Information available through literature,

158 scientific sampling, and fisheries should as much as possible be used to derive parameter

159 estimates and limit the number of parameters to calibrate. There is an abundant literature on

160 optimization procedures for non-linear models (Kleijnen, 1998; Nocedal and Wright, 2006;

161 Walters et al., 1991). This also requires the building of an objective function and the selection

162 of the most appropriate data to fit the model to, keeping in mind this series should preferably

163 not have been used in setting the values for other parameters (see Duboz et al., 2010;

164 Pasandideh and Niaki, 2006). The optimization procedure must be repeated for each

165 formulation of the model created in step 3 since the value of optimized parameters is a

166 function of the other parameter values. If changes are made to the model, the optimization

167 problem is solved anew (Nocedal and Wright, 2006). Once a formulation is calibrated, it

168 presents the best achievable fit to the time series used in the objective function, which may

169 not be perfect, and comparing the fit of various formulations could be a first step toward

170 model selection.

171

172 2.2. Model skill assessment

173 Once all the parameter values are determined, the validation step is carried out by

174 comparison of model outputs with corresponding observations, usually time series. 
175 Information available on the case study should be reviewed including time series of observed

176 data (either from scientific surveys or fishery dependent) and literature knowledge. For

177 validation, hindcast simulations are run with each calibrated formulation during the period for

178 which time series of observations are available, and simulated variables are compared to

179 observations. Unlike calibration, the fit has not been constrained by parameter tuning and the

180 time series have not been used in parameterization. Thus the fit reflects the real predictive

181 power of the model given the formulation assumptions. This power can be quantified against

182 all the available time series using summary statistics. Three commonly used summary

183 statistics have been selected to reflect three complementary aspects of model fit (Stow et al., 184 2009):

- correlation of time series: $r=\left(\sum_{i=1}^{n}\left(O_{i}-\bar{O}\right)\left(P_{i}-\bar{P}\right)\right) /\left(\sqrt{\sum_{i=1}^{n}\left(O_{i}-\bar{O}\right)^{2} \sum_{i=1}^{n}\left(P_{i}-\bar{P}\right)^{2}}\right)$

- model prediction accuracy (mean square error): $M S E=\frac{1}{n} \times \sum_{i=1}^{n}\left(P_{i}-O_{i}\right)^{2}$

- modelling efficiency (Stow et al., 2009):

$$
M E F=\left(\sum_{i=1}^{n}\left(O_{i}-\bar{O}\right)^{2}-\sum_{i=1}^{n}\left(P_{i}-O_{i}\right)^{2}\right) /\left(\sum_{i=1}^{n}\left(O_{i}-\bar{O}\right)^{2}\right)
$$
where $\mathrm{P}_{\mathrm{i}}$ is the $\mathrm{i}_{\text {th }}$ of n model predictions, $\mathrm{O}_{\mathrm{i}}$ the $\mathrm{i}_{\text {th }}$ of $\mathrm{n}$ observations and $\bar{O}$ and $\bar{P}$ are the observation and prediction averages respectively. Correlation ensures that trends are captured, MSE identifies potential biases and reflects accuracy of absolute predictions and MEF measures how well the model predicts relative to the average of the observations. Thus,

193 using the three metrics allows us to characterize trends (r), accuracy (MSE) and efficiency 194 (MEF). 
As a last diagnostic, we propose to assess the impact of inter-annual variation in category (iii) parameters to determine if their value can be averaged in prediction. As suggested by Mackinson et al. (2009), exploratory runs are performed with inter-annual forcing factors relaxed one by one and replaced by their average value. Results are explored using the summary statistics presented above with a focus on correlation.

\section{Materials: ISIS-Fish model of the anchovy fishery in the Bay of Biscay}

The ISIS-Fish model (Mahévas and Pelletier, 2004; Pelletier et al., 2009) has been specifically developed to assess management measures with special emphasis on spatial measures. It uses a common framework for the description of marine populations and exploitation dynamics and describes processes on a discretized 2D space (based on a regular grid defined by the user). ISIS-Fish is a matrix model that accounts for mortality, growth, reproduction and migration to update population numbers monthly, spatially and per population stage. It relies on the basic equation for survival (exponential decay model) and computes fishing mortality based on the dynamically allocated effort of the fishing fleets in

212 the areas where populations and fishing overlap. A management dynamics sub-model 213 enforces regulation constraints on exploitation monthly and spatially as well as fishermen 214 reactions to those constraints. An application of ISIS-Fish has been developed to assess the 215 impact of spatial management measures on the anchovy fishery in the Bay of Biscay. A 216 summary of the equations and parameters is provided in appendix A. The software and the 217 database of this application can be freely downloaded (http://www.isis218 fish.org/download.html). The model consists of around 700 parameters for 17 population 219 stages, 12 months, 15 areas (possibly overlapping, Figure A1), 5 fleets, 14 métiers and 3 gear types (see tables A.1, A.2, A.3 and A.4 for parameter lists and values). The time step is one 
month. The model describes anchovy life cycle including growth, reproduction, recruitment 222 and migrations. The activity of five fleets fishing on anchovy is described through allocation 223 of effort on métiers. Parameters in the initial formulation (Lehuta et al., 2010) were set up by 224 integrating knowledge from literature and experts and by statistical analyses of log-book data 225 for fishing parameters. The model was calibrated on catches at age and visually validated 226 (Lehuta et al., 2010). Parameter values are assessed monthly or seasonally but assumed to be 227 fixed over years. A sensitivity analysis has been performed on the model using group screening, a fractional factorial to explore the parameter space, and a PLS regression

229 (Tenenhaus, 1995) to apportion the variation in multiple model outputs to each group of 230 parameters (Lehuta et al., 2010). The analysis demonstrated that the most sensitive parameters 231 were the biological parameters related to mortality, growth, reproduction and migration. The 232 model was less sensitive to parameters related to fishing. The two exceptions were 233 accessibility and the gear standardisation factor, which standardize effort between gear.

234 Pelletier et al. (2009) and Lehuta et al. (2010) respectively provide full details of model structure and on the formulation initially proposed for the anchovy fishery in the Bay of 236 Biscay. The purpose of this paper is to objectively review this initial formulation, to gain confidence in parameter values, increase transparency in modeling choices and select the most credible parameterization to be used in management strategy evaluation.

\section{Results}

241 Here we present a review of the initial parameterization of the ISIS-Fish model of the Bay of

242 Biscay anchovy and its validation through the methods described above.

243 4.1. Classification of parameters in categories and alternative formulations

244 Based on the results of the sensitivity analysis (Lehuta et al., 2010), the parameters of

245 the model were reviewed and classified in the five categories (Table A.1, A.2, A.3, A.4). 
246 Parameters that were not sensitive were classified in category (i) and kept at their reference

247 value. Growth parameters (Table A.1.V1, 3 parameters) and standardization factors used to 248 standardize effort between gear (Table A.4, 3 parameters), although sensitive and uncertain, 249 were considered properly assessed with the best knowledge at hand, and no alternative 250 methods were proposed to review their values. They were thus assigned to category (ii).

251 Fecundity (Table A.1.R1 and R2, 10 parameters) was also sensitive, but the value is 252 accurately known (Motos, 1996) and belongs to category (ii) as well. Anchovy spawning spatial distributions (Table A.1.S3, 10 parameters) were recorded

254 during scientific surveys. Time spent fishing (Table A.3, 60 parameters) and fishing strategies 255 (Table A.2, 168 parameters) were both assessed from log-books for the period 2000-2008. 256 These parameters all belong to category (iii), that is to say parameters varying in time. Also, 257 larval survival is known to show intrinsic variability, depending on environmental conditions. 258 A time series of estimates of larval survival by year, month and area for the period 2000-2007 was reconstructed based on an individual-based larval drift and survival model (Huret et al., 2010). The bio-physical model predicts the potential survival of larvae depending on

261 spawning area and date of birth (Table A.1.M4, 5 parameters). The effects of annual 262 environmental conditions on larval survival were estimated by fitting an additive linear model 263 to survival rates. In hind-cast simulations over the period 2000-2008, annual values of larval survival, observed stock distribution across spawning areas, and observed fishing effort and strategies of each fleet were used as forcing variables.

Three processes of the model are sensitive and inconsistently or vaguely described in 267 literature. The parameters related to these processes are attributed to Category (iv). The first concerns natural mortality of the first stages, representing the most sensitive parameter of the model. The mortality rate at each stage (15 stages, from eggs to young adults) is determined 270 by adjusting a mortality curve following a Pareto decay (Lo et al., 1995; Table A.1.M3) from 
birth, using the value of egg mortality, to the end of the first reproduction (455 days)

272 assuming that mortality rate is the same as the adults' rate from this stage on (Table A.1.M2, 3 parameters). Two possible estimates of egg mortality were found for Engraulis encrasicolus making the choice uncertain: a survey-based estimate of 0.266 day $^{-1}$ in the Bay of Biscay (2000-2005) (ICES, 2007) and an egg mortality value of 0.565 day $^{-1}$ assessed by Pertierra et al. (1997) in the Catalan Sea (Table A.1.M1). Although the environmental conditions can explain such a difference in estimates for the same species, differences due to measurement error and assessment methods cannot be excluded. Secondly, although quite accurate, fecundity was sensitive which indicates the importance of assumptions related to reproduction

280 parameters in the model. Among them, individual spawning duration has not been

281 characterized precisely (Table A.1.R7, 8 parameters). Pertierra et al. (1997) estimated

282 spawning to last for three months, based on the number of batches and spawning frequency, 283 while Motos (1996) gave a duration of 2.5 months and differentiated between fish of length 284 above and below $14 \mathrm{~cm}$. Thirdly, as seen previously, migration is a sensitive process. The 285 time of departure to the spawning grounds is inaccurately known and described by Uriarte et 286 al. (1996) as occurring in winter, which can correspond to four months (Table A.1.S2).

287 In order to limit the number of formulations that need to be built to reflect the 288 uncertainty in category (iv) parameters, we decided to limit the number of alternatives per 289 uncertain parameter to two. We kept the two alternative values found for egg mortality (ICES 290 estimate Megg1 and the Pertierra et al. (1997) estimate Megg2) as possible starting points for 291 mortality curves (Table A.1.M1). For the spawning duration of small fish (five stages born the 292 previous year in different months), we defined a first hypothesis $\mathbf{R} \mathbf{1}$ in which the two smallest 293 stages (born in July and August of the previous year) spawn during two months only while the 294 other three stages (born earlier in the year) spawn during the full period of three months as 295 adults do. In the alternative hypothesis R2, the three smallest stages (born from June to 
August) spawn for two months only, while the larger fish spawn during three months (Table

297 a.1.R7). Finally two contrasted months of migration to spawning grounds, corresponding to 298 the extremes of the uncertainty range, were considered: January representing the beginning of

299 the winter season (hypothesis MigJ), and April representing the end (hypothesis MigA). The 300 possible formulations are built by combining the discrete values selected for each parameter 301 ( 2 discrete values for 3 parameters result in $8=2 \times 2 \times 2$ combinations).

4.2. Calibration of category (v) parameters

Adult mortality (Table A.1.M2, 3 parameters for 3 adult stages) and accessibility

305

(Table A.1.A, 204 parameters for 17 stages and 12 months) were also sensitive parameters that were both uncertain and hardly measured. Natural mortality can be considered almost constant after the first reproduction (Chen and Watanabe, 1989), that is for anchovy for age 1+ fish. Natural mortality for mature fish is estimated at 1.2 year $^{-1}$ by ICES (ICES, 2009). To assess natural mortality rates for every stage from larvae to recruits, a Pareto model of mortality was fitted using an adult mortality of 1.2 and each of the two egg mortalities previously cited $\left(0.266\right.$ day $^{-1}$ (ICES, 2007) or 0.56 day $^{-1}$ (Pertierra et al. 1997)). The resulting survival rates for the first year were of about $10^{-4}$. This is high and inconsistent with the value of $10^{-5}$ estimated by Petitgas and Massé (2003) based on biomass and recruitment time series and average fecundity, and confirmed using other methods (IBM model, Allain et al., 2007; ) and on another anchovy (E. mordax, Petterman et al., 1988). Higher egg mortality rates or adult mortality rates would be necessary to reach the estimated survival. Estimates of egg mortality being available from field studies, we considered the value 1.2 of adult mortality as questionable and requiring calibration.

Accessibility in ISIS-Fish is the biological component of catchability and quantifies changes in the probability of a fish to be caught due to the biology or the ecology of the stock 
321 (ex. behaviour: burying, schooling)(accessibility and vulnerability sensu Mahevas et al.

322 2011). It is a key parameter of the model as it is one of the parameters which convert effort

323 into fishing mortality. No value was available in the literature for the accessibility parameter.

324 Consequently we relied on expert judgement for the description of the parameter. According

325 to experts, the accessibility of anchovy is mainly age-dependent since area and time variations

326 due to changes in fish density are explicitly modelled, and the schooling behaviour mostly

327 changes after recruitment (P. Petitgas, pers.comm.). Three values of accessibility were thus

328 considered: q0, corresponding to age-0 fish (until the first reproduction); q1, for age-1 and q2,

329 for age-2+. Accessibility parameters and the natural mortality of adults are considered

330 category (v) and needed to be assessed by calibration for each of the eight parameterizations

331 of the anchovy model.

332 For category (v) parameters, the methodology recommends calibration. As natural

333 mortality and accessibility may have confounding effects, a sequential calibration is used to

334 assess parameters related to the two processes independently. We first assess natural mortality

335 of adults. Since the fishery was closed between 2005 and 2008, accessibility values are not

336 necessary to simulate the population over the period. Because the values of natural mortality

337 for larvae and juveniles depend on adult mortality through the Pareto model, the coefficients

338 of the Pareto model are estimated using a range of values for adult mortality $([0.5 ; 3]$ with 0.01

339 increments) and then used to simulate population dynamics over the period 2005-2008.

340 Population growth rate is chosen to be the optimization criterion assuming that mortality is an

341 important driver of biomass trends. The slope of the SSB time series over the period 2005-

3422008 (ICES, 2009) is thus compared to the slope simulated with the set of Pareto models, and

343 the best Pareto model is retained for each of the 8 formulations. Corresponding adult

344 mortality rates are much higher than the value of 1.2 used by ICES (from 1.63 to 3.03

345 depending on the parameterization) (Table 1). 
346 Secondly, we assess accessibility during a period when the fishery was opened (2000-2004).

347 Parameter values for accessibility coefficients q0, q1, q2 are optimised using the variable step

348 simplex algorithm (Walters et al., 1991). The objective function is the sum of squared

349 differences (MSE) (least square minimisation) between the catches at age by quarter reported

350 by ICES (annual reports of the working group for 2001 to 2005, (ICES, 2006; ICES, 2005;

351 ICES, 2004; ICES, 2003; ICES, 2002)) and the simulated ones. Catches at age are chosen

352 because they are directly related to catchability at age through the Baranov equation.

353 Calibrated accessibility values of juvenile fish (before the first reproduction q0) are 100 times

354 lower than those of adults regardless of the model formulation (Table 1). The largest

355 differences between accessibility values (particularly for q1) occur between formulations in

356 which egg mortality differed (Table 1). According to the least squares minimisation between

357 simulated and observed catches, the best fit (smallest MSE) is obtained between simulated

358 and observed catches for the formulation with hypotheses Megg2, R2 and MigJ (Table 1) and

359 more generally for formulations assuming Megg2. This indicates that egg mortality could be

360 higher than the value estimated in the Bay of Biscay.

362 At the end of the parameterisation stage, the use of the uncertainty hierarchy enabled us to

363 reduce the number of parameters to assess or refine from about 700 to 254 (catchability,

364 natural mortality of eggs, larvae per area and of adults, migrations rates to spawning grounds,

365 migration date, fishing time, strategies) among which only 4 are calibrated (category (v):

366 adult natural mortality, q0, q1, q2). The calibration process (in two stages natural mortality

367 first then catchability using the simplex) required about 1500 simulations for all 8

368 formulations. 
Available observations for validation purposes are: the absolute index of biomass and

372 recruitment biomass annually obtained by acoustics (PELGAS surveys, IFREMER, ICES, 2009), the average distribution of egg production per month over the spawning season (Allain 2004 (French database Harmonie, FIS, IFREMER; Spanish data, Leire Ibaibarriaga, pers. comm.), and the annual total biomass of catch over the period 2000-2004 (ICES, 2006). Although used for calibration, the values of summary statistics for the seasonal catch in numbers at age per country are considered in the assessment of model skill (ICES 2006; ICES 2005; ICES, 2004; ICES, 2003, ICES, 2002).

The three summary statistics are examined successively. Temporal correlations range

381 from 0.18 for the catches at age 2 to 0.99 for spawning distributions (Figure 2, r). Although

382 the models are calibrated for minimum squared differences on catches at age, the temporal 383 correlations seldom exceed 0.8 for these output variables. Correlation values do not differ 384 much between formulations, except for catches at age 2, for which hypotheses Megg2 and 385 MigA appears more suitable (Figure 2, r). MSE values differ considerably between output variables because of the variety of 387 metrics and temporal scales. To be able to compare alternative formulations across output 388 variables, the value displayed on the radar plot is the rank of each formulation according to its 389 MSE value (8 corresponding to the lowest MSE value: best, 1 to the highest: worst) (Figure 2, 390 MSE). The rank of a formulation highly depends on the output variable considered. Annual 391 catches (Catch/y), catches at age (Cage), biomass and spawning distribution (Sp. Distr.) 392 appear more accurately reproduced using models with hypotheses Megg2 and MigA, while 393 Megg1 gives better fit to catches of trawler fleets (CPel) (Figure 2, MSE). The representation 394 using ranks enables formulations to be compared according to spawning distribution when 395 they perform identically according to MEF and correlation (Sp. Distr., Figure 2, MSE). 
Spawning distribution is probably the most direct consequence of the hypotheses on reproduction patterns. Confrontation of simulated and observed time series (not shown), evidences that the spatial and temporal distribution of egg production is close to the average pattern reported by Allain et al. (2007), although inter-annual variations are important particularly in July. Differences mostly concern the month in which egg production peaks.

Combining Megg2 and R1is necessary to simulate a peak in egg abundance in June as observed. Therefore spawning duration for most of the age-1 fish could be as long as that of age-2 (R1) and spawning timing is probably influenced by age structure (Megg 2). the observation average would be a better predictor than the model results (Figure 2, MEF). In particular, modelled catches of purse seiners profile 1 (CBol1), and trawlers profile 2 (CPel 2) are far from observations. This is mainly due to the opportunism of these fleets. Anchovy is not their main target, and they catch it occasionally when they encounter a school, which is hardly described by the model because the time step is the month and the movements of fish schools are not simulated. Here again, the best model depends on the output variable

411 considered (Figure 2, MEF). Formulations with Megg2 give poor results when considering 412 catches of trawler fleets (particularly CPel2), mostly because catches in the first year are overestimated, but these formulations are appropriate for the majority of the other outputs.

414 Given the good performances across almost all output variables, we use the formulation with

415 Megg2, R1 and MigA, in the following to investigate the impact of inter-annual variability on 416 the modelled dynamics.

\subsection{Impact of inter-annual variability}

419 Exploratory simulations are run with the selected formulation (egg mortality hypothesis 420 Megg2, first reproduction function (R1) and migration of adults in April (MigA)). Each 
output variable reacts differently and reveals the process that mostly impacts its dynamics

422 (Figure 3). The effect of relaxing a forcing (using average values) is seen by comparing the forced model (black line) to the model with average values for the process considered.

424 Biomass, catches at age 0, recruitment and catches of purse seiners fleets, are highly

425 influenced by the forcing by larval survival (Figure 3, Average Survival"). Releasing the

426 forcing generally improves the correlation except for catches at age 0 , showing that the

427 processes occurring between egg and recruit stages are not fully resolved using the individual-

428 based larval drift and survival model. However, visual validation showed that the use of the

429 forcing by the larval survival time series improves the reproduction of the biomass trend with

430 the exception of year 2002 (Figure 4). Average migration rates have a low impact and

431 generally decrease correlation while average effort substantially decreases the correlation for

432 purse seiners profile 1 (Figure 3). Consequently, scenarios are needed for larval survival and

433 migration, as they largely influence the dynamics. On the other hand, the average effort and

434 strategies should be appropriate for most of the fleets except for purse seiner profile1

435 (CBol1).

436

437 5. Discussion

438 Ideally integrated estimation using multiple time series and objective functions is performed

439 to assess parameter values in a complex model. Many methods exist to address parameter

440 estimation (both discrete and continuous) and model selection, in both frequentist and

441 Bayesian frameworks, as long as a likelihood function can be built and simulation costs are

442 not limiting. Autodifferentiation as proposed by the software ADMB is often used for fishery

443 models (http://www.otter-rsch.com/; Drouineau et al., 2010). Markov processes and

444 Bayesian frameworks when usable offer transparent ways to deal with various sources and the 445 nature of uncertainty (Hillary et al., 2012; Williams, 2011; Bertorelle et al., 2010). 
Two major difficulties linked to the nature of our model prevented the use of an integrated optimization procedure and motivated the development of the proposed methodology: (1) the duration of simulations, which constrained the model to be deterministic and the optimization procedure to be limited to few parameters; and (2) its complexity, which prevents a likelihood function to be defined. We also needed a procedure which could deal with discrete parameters, like integers (months) or formulas (reproduction duration) or even more complex (spatial limits of areas) as well as continuous parameters, a situation not well handled by common optimization algorithms (based on computation of derivative for instance). In addition, an integrated estimation (e.g. using likelihood) would require many data sources and their compliance with model assumptions, a situation seldom encountered (Pech et al., 2001). An alternative would have been the building of a metamodel, for instance using response surface methodology, to decrease simulation time and allow the methods cited above to be used (Myers et Montgomery, 2002).

However, the building of a metamodel could itself be time consuming and delicate. In such cases, our procedure offers a pragmatic and transparent way to use all available information to

461 provide parameter estimates and evaluate the credibility of the model. To limit computation

462 time and prevent identifiability problems, the optimization was restrained to as few parameters as possible based on a sensitivity analysis and a classification of sensitive uncertain parameters into 3 categories according to the nature of their uncertainty. Calibration was used for only one of these categories and alternative formulations were considered.

466 Although an effort was made towards rational attribution of parameters to categories, it 467 cannot be denied that the classification is partly subjective. Similarly, the solutions provided 468 to treat each category do not pretend to be unique and other treatments could be proposed. 469 The assessed values for category (ii) for instance, although less uncertain, are unlikely to be 470 exact, and confidence intervals or distribution laws could have been used to create predictive 
distributions for model outputs. Category (iii) processes were treated as forcing variables. In a

472 less computer-intensive model, they could have been considered latent processes and a

473 stochastic procedure run to assess the process error associated, as is done in state-space

474 modelling in Bayesian frameworks (Harwood \& Stokes, 2003). In a deterministic context, one

475 can also propose alternative underlying mechanisms possibly responsible for these variations

476 and compare their fit; they would then belong to category (iv). The alternative values found

477 for category (iv) were interpreted as inconsistent or conflicting. It is actually rational that

478 different cases study or methodologies (empirical, model estimates) or time periods of

479 observations give different estimates, and the uncertainty could be described as resulting from

480 process or measurement error. Optimization for these parameters could have resulted in a new

481 estimate, possibly different from those found in the literature. Keeping alternative model

482 formulations can be compulsory when, for instance, the inconsistency concerns incompatible

483 model structures. Since the number of alternative formulations can rapidly increase, it could

484 be necessary to limit their definition by adopting other sampling strategies of the parameter

485 space or by eliminating unlikely combinations.

486 Keeping alternative formulations presents the advantage of guaranteeing that parameters are

487 meaningful outside the model context. Indeed, the value of parameters estimated through an 488 optimization procedure is conditional to assumptions made elsewhere in the model, and may

489 thus compensate for the value of other parameters to achieve a good fit. The estimate of adult

490 mortality can be discussed as an example. First, the short duration of the calibration period

491 (only four years) gives low robustness to the mortality estimate. Second, the values appeared

492 very sensitive to other assumptions of the model. The value of 3.03 for instance was out of

493 range according to experts. It should be interpreted in the context of our model as it

494 compensates for higher early survival and reproduction success estimates. 
495 Both for calibration and validation, the observations should be distinguished from the truth

496 (Lynch et al., 2009). Observation data may be subject to errors, for instance landings reported

497 in log-books may be incomplete or erroneous. Ideally, validation data must be directly

498 observed, and not the result of an estimation process, because the estimation methods might

499 use assumptions inconsistent with the assumptions of the model. Here the model was

500 validated using indices of biomass estimated by acoustics, which do not involve any

501 biological knowledge on anchovy. Anchovy biomass estimated by ICES was also available,

502 however it is the result of an assessment model (ICES, 2009) for which assumptions

503 regarding recruitment (random) and adult mortality (1.2) differed from ours. Even the indices

504 of biomass estimated using the Daily Egg Production Method required parameters also used

505 in the model (fecundity and egg mortality). Although the use of acoustic data was

506 recommended for validation, the comparison with the other time series (Figure 4) informed of

507 the uncertainty around biomass and increased our confidence in model realism.

508 Anchovy being well documented in the Bay of Biscay, we were able to corroborate model

509 outputs against multiple time series not used in parameterization. This could be seen as a

510 concrete application of pattern oriented modelling through the validation of secondary

511 predictions' (Wiegand et al., 2003). The use of several time series of outputs, which result

512 from the interaction of multiple parameters, guaranteed the model _structural realism'. In

513 effect, the model cannot reproduce simultaneously multiple patterns observed at different

514 scales and hierarchical levels, if key processes are not captured realistically (Cury et al.,

515 2008). Secondly, because of the multiple, confounding factors that can have synergistic or

516 antagonistic effects on fishery dynamics, one needs more than a single series of observations

517 to distinguish between several hypotheses of description for a phenomenon (Mackinson et al.,

518 2009). It enables model developers to filter unlikely combinations of hypotheses even if their

519 effects are generally confounded. For instance, model fit on biomass was equivalent across 
parameterizations, as biomass is mainly driven by variation in recruitment. However, the underestimation of egg mortality in parameterizations with Megg1 induced incompatible low proportions of age- $2+$ in the population and very low catches for these classes. Allen and Somerfield (2009) also propose to validate the relationships between model variables to guaranty the realism of model emergent properties.

Here we tried to make the validation step more objective by quantifying model skill through three statistical criteria. This approach is largely applied for validation of coupled physicalbiological models (Allen and Somerfield, 2009; Jolliff et al., 2009; Stow et al., 2009) that often make use of geo-referenced validation data. No agreement exists on the best and number of criteria to use, and they must be selected according to the kind of confidence the user wants to acquire on its model (see Sterman, 1984, for a classification of possible confidence tests). The rational for the three we chose was that they summarised 3 important aspects of model fit we were interested in and are probably of importance for any fishery model. Indeed, (i) small MSE ensures that absolute values can be used in prediction (TAC, reference points, etc); (ii) good correlations prove that mechanisms responsible for past trends are understood and (iii) efficiency informs on variables that could be replaced by the average of the observations and should not be trusted in prediction. They offer complementary information, for instance showing that although catch realised by the trawler fleet profile 2 is well correlated with observations, it does not perform better than the average time series. Other criteria proposed in the literature were reliability index (Stow et al., 2003), the normalised standard deviations (Jolliff et al., 2009), and rank correlations (Allen and Somerfield, 2009). Further developments of summary statistics for time series and spatial data would also be interesting to consider in further studies. It was implicitly done here as output variables had various time and spatial aggregation levels (but see Bellassen et al., 2011 for explicit account of three 
545 spatial scales in validation). We presented multivariate results using radar plots for each

546 criterion to allow visual comparison of the variables. Alternatively, Jolliff et al. (2009),

547 proposed summary diagrams such as Taylor diagrams together with reference points to help

548 summarise one model's skill, while Allen and Somerfield (2009) relied on multivariate

549 analyses.

550 Finally, validation will ever be in some ways arbitrary as long as no reference values for

551 summary statistics are unanimously accepted. An advantage of our method is that it

552 transparently evidenced the trade-offs, strengths and weaknesses of modeling choices. Even if

553 reproducing time series were to give confidence in the model, as advocated by Mackinson et

554 al. (2009), failures in fitting the model were also informative and offered the opportunity to

555 reveal gaps in the current understanding of the system and provide indications of where

556 further knowledge could be usefully gained. We identified weaknesses in the simulated

557 dynamics of catches at age 0 and 2 and catches of purse seiners from Brittany.

558 In the present case, none of the formulations was unanimously supported, neither across

559 summary statistics, nor across output variables. It is nevertheless possible to conclude that a

560 high value of egg mortality, surprisingly closer from the value observed in the Mediterranean

561 than in the Atlantic, was necessary to reproduce the dynamics of validation data (except

562 catches of pair trawler fleets). The choice of a single formulation among the eight evaluated

563 requires trade-offs. In many cases, experts help in sorting hypotheses or weight knowledge

564 sources according to their reliability (Stefansson, 1998). However, reliability could be hard to

565 determine. When the sources are so conflicting that the model cannot explain all the data

566 sources simultaneously, Pech et al. (2001) proposed an iterative procedure of partial fit, and

567 Stefansson (1998) suggested questioning model structure. If a valid likelihood function can be

568 constructed, the Akaike criteria or Bayesian approaches are well adapted to assign weights to

569 alternative assumptions (see for instance Patterson, 1999). Recent emergence of Approximate 
Bayesian Computation offers a more flexible framework to choose between models

571 (Beaumont, 2010). Model averaging is also an option and is used for instance if the structures

572 of the available models are very different (climate models for instance, Hill et al., 2007).

573 Otherwise alternative hypotheses should normally be stored for inclusion in uncertainty 574 analyses (Hill et al., 2007). Here we gave preference to a formulation that was performing 575 satisfyingly on every variable rather than the best on one variable; this choice is of course 576 debatable. Despite the weaknesses evidenced, we deem that the main processes of the 577 anchovy fishery dynamics were understood and successfully modelled. The model was 578 developed to assess the impact of marine protected areas on the anchovy fishery and given the 579 validation results, we are confident that any of the eight formulations (ideally all eight) could 580 be used to support management decisions. It would have to be run within an uncertainty 581 framework that ensures that all sources of uncertainty are covered. Additionally, scenarios or random trajectories of inter-annual variations in larval survival and migration rates should be 583 tested.

\section{Acknowledgements}

This study was carried out with financial support from the Commission of the European

587 Communities as a contribution to FP6 Specific Targeted Research Project 022717

588 (UNCOVER). Authors are grateful to Jacques Masse (IFREMER) for his expertise on the 589 fishery. We thank Leire Ibaibarriaga (AZTI) for supplying the data on the Spanish Basque 590 fishery 2000-2003 and for expert advice on its parameterization. We thank Kathy Mills for 591 her precious editing comments. Technical support on ISIS-Fish was warranted by the private 592 company Code Lutin. The official French catch and effort data were extracted from 593 Harmonie, a database containing the Fisheries Information System managed by IFREMER. 


\section{References}

597 Allain, G., Petitgas, P., Lazure, P., and Grellier, P., 2007. Biophysical modelling of larval 598 drift, growth and survival for the prediction of anchovy (Engraulis encrasicolus) 599 recruitment in the Bay of Biscay (NE Atlantic). Fisheries Oceanography. 16(6), 489-505. 600 Allen, J.I., Somerfield, P.J., and Gilbert, F.J., 2007. Quantifying uncertainty in high-resolution 601 coupled hydrodynamic-ecosystem models. Journal of Marine Systems. 64, 3-14.

602 Allen, J.I., and Somerfield, P.J., 2009. A multivariate approach to model skill assessment. 603 604 605

Bellassen, V., le Maire, G., Guin, O., Dhôte, J., Ciais, P., and Viovy, N., 2011. Modelling 608 forest management within a global vegetation model-Part 2: Model validation from a tree to a continental scale. Ecological Modelling. 222, 57-75.

Bertorelle, G., Benazzo, A., and Mona, S., 2010. ABC as a flexible framework to estimate

Charles, A., 1998. Living with uncertainty in fisheries: analytical methods, management priorities and the Canadian groundfishery experience. Fisheries Research. 37, 37-50.

615 Chen, S., and Watanabe, S., 1989. Age dependence of natural mortality coefficient in fish 616 population dynamics. Nippon Suisan Gakkaishi. 55(2), 205-208.

617 Cury, P.M., Shin, Y., Planque, B., Durant, J.M., Fromentin, J., Kramer-Schadt, S.et al., 2008. 618 Ecosystem oceanography for global change in fisheries. Trends in Ecology and Evolution. $619 \quad 23,338-346$. 
Drouineau, H., Mahevas, S., Bertignac, M., and Duplisea, D., 2010. A length-structured spatially explicit model for estimating hake growth and migration rates. ICES Journal of Marine Science. 67, 1697-1709.

Duboz, R., Versmisse, D., Travers, M., Ramat, E., and Shin, Y., 2010. Application of an evolutionary algorithm to the inverse parameter estimation of an individual-based model. Ecological Modelling. 221, 840-849.

Fulton, E.A., Smith, A.D.M., and Johnson, C.R., 2004. Biogeochemical marine ecosystem models I: IGBEM — a model of marine bay ecosystems. Ecological Modelling. 174, 267307.

Harwood, J., Stokes, K., 2003. Coping with uncertainty in ecological advice: lessons from fisheries. 18, 617-622.

Hill, S.L., Watters, G.M., Punt, A.E., McAllister, M.K., Le Quere, C., and Turner, J., 2007. Model uncertainty in the ecosystem approach to fisheries. Fish and Fisheries. 8, 315-336.

Hillary, R.M., Levontin, P., Kuikka, S., Manteniemi, S., Mosqueira, I., and Kell, L., 2012. Multi-level stock-recruit analysis: Beyond steepness and into model uncertainty. Ecological Modelling. 242, 69-80.

Huret, M., Petitgas, P., and Woillez, M., 2010. Dispersal kernels and their drivers captured with a hydrodynamic model and spatial indices: A case study on anchovy (Engraulis encrasicolus) early life stages in the Bay of Biscay. Progress in Oceanography. 87, 6-17. ICES. 2002. Report of the Working Group on the Assessment of Mackerel, Horse Mackerel, Sardine and Anchovy. ICES CM 2002/ACFM:06: pp.

ICES. 2003. Report of the Working Group on the Assessment of Mackerel, Horse Mackerel, Sardine and Anchovy. ICES CM 2003/ACFM:07: pp.

ICES, 2004. Report of the Working Group on the Assessment of Mackerel, Horse Mackerel, Sardine and Anchovy. ICES CM 2004/ACFM:08. , . 
645 ICES. 2005. Report of the Working Group on the Assessment of Mackerel, Horse Mackerel,

646 Sardine and Anchovy. ICES CM 2005/ACFM:08: pp.

647 ICES. 2006. Report of the Working Group on the Assessment of Mackerel, Horse Mackerel,

648 Sardine and Anchovy. ICES CM 2006/ACFM:36ICES CM 2006/ACFM:36.

649 ICES. 2007. Report of the working group on the assessment of mackerel, horse mackerel,

650 sardine and anchovy. ICES CM 2007/ACFM:31.

651 ICES. 2009. Report of the Working Group on Anchovy and Sardine. ICES CM

652 2009/ACOM:13, 354pp.

653 Jolliff, J.K., Kindle, J.C., Shulman, I., Penta, B., Friedrichs, M.A.M., Helber, R.et al., 2009.

654 Summary diagrams for coupled hydrodynamic-ecosystem model skill assessment. Journal 655 of Marine Systems. 76, 64-82.

656 Kleijnen, J.P.C. 1998. Experimental Design for Sensitivity Analysis, Optimization, and

657 Validation of Simulations Models. In Handbook of simulation. Principles, Methodology,

658 Advances, Applications and Practise. Banks, J. Wiley, New York. Engineering and

659 Management Press (Ed.). 173-224.

660 Kraus, G., Pelletier, D., Dubreuil, J., Moellmann, C., Hinrichsen, H., Bastardie, F.et al., 2009.

661 A model-based evaluation of Marine Protected Areas: the example of eastern Baltic cod

662 (Gadus morhua callarias L.). ICES Journal of Marine Science. 66, 109-121.

663 Lehuta, S., Mahévas, S., Petitgas, P., and Pelletier, D., 2010. Combining sensitivity and

664 uncertainty analysis to evaluate the impact of management measures with ISIS-Fish:

665 marine protected areas for the Bay of Biscay anchovy (Engraulis encrasicolus) fishery.

666 ICES journal of marine science. 67, 1063-1075.

667 Lo, N., Smith, P., and Butler, J., 1995. Population growth of the northern anchovy and pacific

668 sardine unsing stage-specific matrix models. Marine Ecology Progress Series. 127, 15-26. 
Lynch, D.R., Jr, D.J.M., and Werner, F.E., 2009. Skill assessment for coupled biological/physical models of marine systems. Journal of Marine Systems. 76, 1 - 3.

Mackinson, S., Daskalov, G., Heymans, J.J., Neira, S., Arancibia, H., Zetina-Rejón, M.et al., 2009. Which forcing factors fit? Using ecosystem models to investigate the relative influence of fishing and changes in primary productivity on the dynamics of marine ecosystems. Ecological Modelling. 220, 2972-2987.

Mahevas, S., Trenkel, V.M., Doray, M., Peyronnet, A., 2011. Hake catchability by the French trawler fleet in the Bay of Biscay: estimating technical and biological components. ICES Journal of Marine Science. 68, 107-118.

Mahévas, S., and Pelletier, D., 2004. ISIS-FISH, a generic and spatially explicit simulation tool for evaluating the impact of management measures on fisheries dynamics. Ecological Modelling. 171, 65-84.

Motos, L., 1996. Reproductive biology and fecundity of the Bay of Biscay anchovy population (Engraulis encrasicolus L). Scientia Marina. 60, 195-207.

Myers, R H, and Montgomery, D.C. 2002. Response Surface Methodology, second ed. Wiley Series in Probability and Statistics.

Nocedal, J., and Wright, S.J. 2006. Numerical Optimization, 2nd Ed. Mikosch, T. V., Resnick, S. I. , and Robinson, S. M. (Eds.). Springer Series in Operations Research, New York.

Pasandideh, S.H.R., and Niaki, S.T.A., 2006. Multi-response simulation optimization using genetic algorithm within desirability function framework. Applied Mathematics and Computation. 175, 366-382.

Patterson, K., 1999. Evaluating uncertainty in harvest control law catches using Bayesian Markov chain Monte Carlo virtual population analysis with adaptative rejection sampling 
and including structural uncertainty. Canadian Journal of Fisheries and Aquatic

$694 \quad$ Sciences. 56, 208-221.

695 Pech, N., Samba, A., Drapeau, L., Sabatier, R., and Laloë, F., 2001. Fitting a model of

696 flexible multifleet-multispecies fisheries to Snegalese artisanal fishery data. Aquatic

$697 \quad$ Living Resources. 14, 81-98.

698 Pelletier, D., Mahevas, S., Drouineau, H., Vermard, Y., Thebaud, O., Guyader, O.et al., 2009.

699 Evaluation of the bioeconomic sustainability of multi-species multi-fleet fisheries under a

700 wide range of policy options using ISIS-Fish. Ecological Modelling. 220, 1013 - 1033.

701 Pelletier, D., and Mahévas, S., 2005. Fisheries simulation models for evaluating the impact of

702 management policies, with emphasis on marine protected areas. Fish and Fisheries. 6,

$703 \quad 307-349$.

704 Pertierra, J., Lleonart, J., and Lo, N., 1997. Application of a stage-specific matrix model and 705 length-cohort based analysis to assess the anchovy fishery in Catalan coastal waters (NW Mediterranean Sea). Fisheries Research. 30, 127-137.

Petitgas, P., and Massé, J.. 2003. Orders of magnitude for some biological processes in Biscay anchovy population. Working document of the ICES Working Group on the Assessment of Mackerel, Horse Mackerel, Sardine and Anchovy. Working document of the ICES Working Group on the Assessment of Mackerel, Horse Mackerel, Sardine and Anchovy. Copenhagen, 9-19 September 2003.

Peterman, R.M., Bradford, M.J., Lo, N.C., Methot, R.D., 1988. Contribution of early life

714 Fisheries and Aquatic Sciences. 45, 8-16.

Punt, A.E., Donovan, G.P., 2007. Developing management procedures that are robust to 
718 Saltelli, A., Chan, K., and Scott, E. 2000. Sensitivity Analysis. Saltelli A, Chan, K. , and Scott, E. (Eds.). Wiley.

Stefansson, G. 1998. Comparing different information sources in a multispecies context. In Fishery Stock Assessment Models. Alaska Sea Grant College Program (Ed.). 741-758.

Sterman, J. D. 1984. Appropriate summary statistics for evaluating the historical fit of system dynamics models. Dynamica. 10 (Winter), 51-66.

Stow, C.A., Jolliff, J., McGillicuddy, Jr., Dennis J., Doney, S.C., Allen, J.I., Friedrichs, M.A.M.et al., 2009. Skill assessment for coupled biological/physical models of marine systems. Journal of Marine Systems. 76, 4-15.

Stow, C.A., Roessler, C., Borsuk, M., Bowen, J., and Reckhow, K., 2003. A comparison of estuarine water quality models for TMDL development in the Neuse River Estuary. Journal of Water Resources Planning and Management. 129, 307-314.

Tenenhaus, M., Gauchy, J.P., Ménardo, C., 1995. Régression PLS et applications. Tome 43, $n^{\circ} 1,7-63$.

Travers, M., Shin, Y., Shannon, L., Cury, P., 2006. Simulating and testing the sensitivity of ecosystem-based indicators to fishing in the southern Benguela ecosystem. Canadian Journal of Fisheries and Aquatic Sciences. 67, 943-956.

Uriarte, A., Prouzet, P., Villamor, B., 1996. Bay of Biscay and Ibero Atlantic anchovy populations and their fisheries. Scientia Marina. 60 (Suppl. 2), 237-255. optimization: a technique for improving quality and productivity in research, development, and manufacturing (Chemometrics series). Walters, F. H., Parker, L. R., 
741 Wiegand, T., Jeltsch, F., Hanski, I., and Grimm, V., 2003. Using pattern-oriented modeling

742 for revealing hidden information: a key for reconciling ecological theory and application.

743 Oikos. 100, 209-222.

744 Wiegand, T., Revilla, E., and Knauer, F., 2004. Dealing with uncertainty in spatially explicit 745 population models. Biodiversity and Conservation. 13, 53-78.

746 Williams, B.K., 2011. Resolving structural uncertainty in natural resources management 747 using POMDP approaches. Ecological Modelling. 222, 1092-1102.

748 
Appendix A: ISIS-Fish model, equations and parameters of the Bay of Biscay anchovy application

ISIS-Fish is a matrix model based on three sub-models for populations, fleets and management. The population sub-model describes the processes that occur seasonally in the different areas defined for the population(s) (growth, natural mortality, reproduction, migrations). At each time step, the model updates population numbers per age- or size class and area according to those biological processes and to the natural and fishing mortality suffered (eq. 1).

$$
N(t+1)=S R(t) R(t)+D_{\text {season }}^{\text {mig }} C C_{\text {season }} N(t)+N_{\text {season }}^{\text {immig }}(\text { eq. } 1)
$$

where $\mathrm{N}(\mathrm{t})$ and $\mathrm{N}(\mathrm{t}+1)$ are the area- and class-specific matrix of population numbers at time $\mathrm{t}$ and $t+1 . R(t)$ is the recruitment vector, $D^{\text {mig }}$ season is the migration matrix, $N^{\text {immig }}$ season is the immigration vector, $\mathrm{CC}_{\text {season }}$ is the matrix depicting change of class due to aging in the case of an age-structured model, and to individual growth in the case of a stage-structured model and $\mathrm{SR}(\mathrm{t})$ is the diagonal matrix of survival rates of the population between time $t$ and $t+1$.

The anchovy population was modeled with 17 stages, 15 from spawning to first reproduction to account for mortality at each stage and variation in size when first reproducing due to early/late hatching. The population migrate seasonally from the north of the Bay of Bicay to spawning areas and back (Figure A.1, table A.1).

Survival rate is computed according to the classic exponential decay model (eq 2):

$s r(c, z p o p, t)=\exp (-(F(c, z p o p, t)+M(c, z p o p) / 12))($ eq.2)

where $\mathrm{c}$ is age- or size-class, zpop is population zone, $\mathrm{F}$ is the fishing mortality rate $\left(\mathrm{month}^{-1}\right)$ and $\mathrm{M}$ natural mortality rate $\left(\mathrm{year}^{-1}\right)$ that can vary with seasons and areas. 
The fleet dynamics sub-model describes the spatio-seasonal distribution of fishing effort according to vessels characteristics, métiers, and annual fishing strategies. It computes fishing mortality for each population area based on fishing effort in the overlapping fishing areas. Effort is deduced from fishing time depending on several standardization factors for métiers (target factors) and gear (gear standardization factor and selectivity coefficient) (table A.2).

The anchovy fishery is described by 5 fleets according to gear used (purse seine or pair trawl), home harbor (Brittany, Basque Country, Spain, La Tuballe). Number of vessels in a fleet is the 2000-2003 average. Each fleet displays different fishing strategy, characterized by the distribution of monthly effort on each possible métier (table A.2). Métiers were identified at the fishing operation scale by gear used, area of practice and catch profile. They are characterized by target factors (mean percentage of anchovy in the landings per métier trip per month) (table A.2). Gears standardization factors were computed by statistical analyses of catch per unit of effort data and no selectivity function is assumed; all fish above $9 \mathrm{~cm}$ are caught (table A.4). Total fishing time per vessel and month for each fleet is the average over boats and over the period 2000-2004 (Table A.3). It is distributed among métiers according to monthly proportions (Table A.2) computed as the 2000-2004 averages.

Management dynamics sub-model enforces regulation constraints on exploitation monthly and spatially as well as fishermen reactions to those constraints. We assumed no constraints on the fishery for the period 2000-2004 preceding the closure.

Except for the last part of the study (impact of inter-annual variations) parameter values are fixed for the entire simulation period. 


\begin{tabular}{|c|c|c|c|c|c|c|c|c|c|c|c|}
\hline \multirow{10}{*}{$\begin{array}{l}\text { Hindca } \\
\text { st } \\
\text { models } \\
\text { forced } \\
\text { by past } \\
\text { time } \\
\text { series }\end{array}$} & \multicolumn{3}{|c|}{ Parameterizations } & \multicolumn{4}{|c|}{ Calibrated parameters } & \multicolumn{2}{|c|}{$\begin{array}{l}\text { Comparison } \\
\text { within } \\
\text { formulations }\end{array}$} & \multirow{2}{*}{$\begin{array}{l}\text { Compari } \\
\text { son } \\
\text { across } \\
\text { formulati } \\
\text { ons } \\
\text { q1(for- } \\
\text { mulation } \\
\text { i) / } \\
\text { q1(for- } \\
\text { mulation } \\
\text { 1) } \\
\end{array}$} & \multirow[t]{2}{*}{ MSE } \\
\hline & \begin{tabular}{|l} 
Egg \\
mortali \\
ty
\end{tabular} & $\begin{array}{l}\text { Repro- } \\
\text { duction } \\
\text { duration }\end{array}$ & $\begin{array}{l}\text { Migration } \\
\text { date }\end{array}$ & $\begin{array}{l}\text { Adult } \\
\text { morta- } \\
\text { lity }\end{array}$ & q0 & q1 & q2 & $q 0 / q 2$ & $q 1 / q 2$ & & \\
\hline & \multirow{4}{*}{$\begin{array}{l}\text { Megg1 } \\
= \\
0.266 \\
\text { day }^{-1}\end{array}$} & \multirow[t]{2}{*}{ R1 } & April & \multirow[b]{2}{*}{$\begin{array}{l}3.03 \\
\mathrm{yr}^{-1}\end{array}$} & $\begin{array}{l}3.56 \\
e-5\end{array}$ & $\begin{array}{l}4.68 \\
e-3\end{array}$ & $\begin{array}{l}2.20 \\
e-3\end{array}$ & 0.02 & 2.12 & 1.00 & $2.66 \mathrm{e} 18$ \\
\hline & & & January & & $\begin{array}{l}3.23 \\
e-5 \\
\end{array}$ & \begin{tabular}{|l|}
4.46 \\
$e-3$ \\
\end{tabular} & \begin{tabular}{|l|}
2.41 \\
$e-3$
\end{tabular} & 0.01 & 1.85 & 0.95 & $2.70 \mathrm{e} 18$ \\
\hline & & \multirow[t]{2}{*}{ R2 } & April & \multirow[b]{2}{*}{$\begin{array}{l}2.97 \\
\mathrm{yr}^{-1}\end{array}$} & $\begin{array}{l}3.59 \\
e-5\end{array}$ & $\begin{array}{l}4.48 \\
e-3\end{array}$ & $\begin{array}{l}2.18 \\
e-3\end{array}$ & 0.02 & 2.05 & 0.96 & $2.62 \mathrm{e} 18$ \\
\hline & & & January & & $\begin{array}{l}3.30 \\
e-5\end{array}$ & $\begin{array}{l}4.29 \\
e-3\end{array}$ & $\begin{array}{l}2.36 \\
e-3\end{array}$ & 0.01 & 1.82 & 0.92 & $2.66 \mathrm{e} 18$ \\
\hline & \multirow{4}{*}{$\begin{array}{l}\text { Megg2 } \\
= \\
0.565 \\
\text { day }^{-1}\end{array}$} & \multirow[t]{2}{*}{ R1 } & April & \multirow[b]{2}{*}{$\begin{array}{l}1.67 \\
\mathrm{yr}^{-1}\end{array}$} & $\begin{array}{l}8.98 \\
e-5\end{array}$ & $\begin{array}{l}2.66 \\
e-3\end{array}$ & \begin{tabular}{|l|}
2.70 \\
$e-3$
\end{tabular} & 0.03 & 0.99 & 0.57 & $2.36 \mathrm{e} 18$ \\
\hline & & & January & & $\begin{array}{l}8.35 \\
e-5\end{array}$ & $\begin{array}{l}2.27 \\
e-3\end{array}$ & $\begin{array}{l}3.31 \\
e-3\end{array}$ & 0.03 & 0.69 & 0.49 & $2.35 \mathrm{e} 18$ \\
\hline & & \multirow[t]{2}{*}{$\mathbf{R 2}$} & April & \multirow[b]{2}{*}{$\begin{array}{l}1.63 \\
\mathrm{yr}^{-1}\end{array}$} & $\begin{array}{l}8.44 \\
e-5\end{array}$ & \begin{tabular}{|l|}
2.59 \\
e-3
\end{tabular} & \begin{tabular}{|l|}
2.70 \\
$e-3$
\end{tabular} & 0.03 & 0.96 & 0.55 & $2.29 \mathrm{e} 18$ \\
\hline & & & January & & $\begin{array}{l}7.67 \\
e-5\end{array}$ & \begin{tabular}{|l}
2.18 \\
e-3
\end{tabular} & \begin{tabular}{|l}
3.23 \\
$e-3$
\end{tabular} & 0.02 & 0.68 & 0.47 & $2.28 \mathrm{e} 18$ \\
\hline
\end{tabular}

Table 1: Calibration results of the adult natural mortality and accessibility coefficients (q0, q1 and q2) and corresponding minimum squared errors (MSE) between simulated and observed catches at age per quarter, for different scenarios of egg mortality, reproduction duration and migration date. Ratios of values at age (q0/q2; q1/q2) ease comparison within a formulation. Ratios of q1values obtained for each formulation help comparison between formulations. 


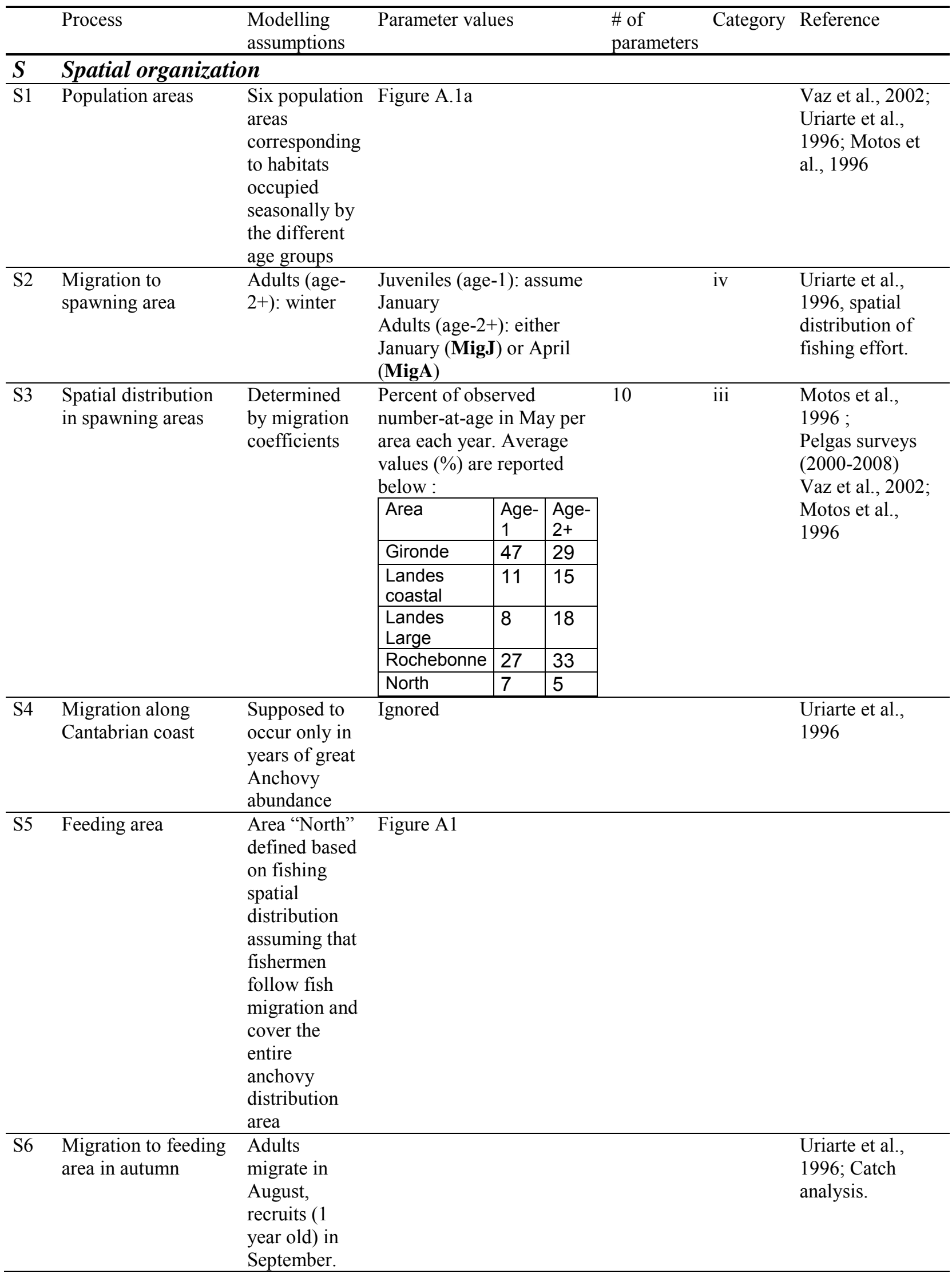




\begin{tabular}{|c|c|c|c|c|c|c|}
\hline S7 & $\begin{array}{l}\text { Population spatial } \\
\text { distribution in } \\
\text { autumn and winter }\end{array}$ & $\begin{array}{l}\text { Determined } \\
\text { by migration } \\
\text { coefficients }\end{array}$ & $\begin{array}{l}65 \% \text { of age- } 1+\text { biomass is } \\
\text { in area "North" (Figure 1) }\end{array}$ & 10 & ii & Evohe surveys \\
\hline S8 & $\begin{array}{l}\text { Larval drift and } \\
\text { juvenile } \\
\text { concentration in } \\
\text { coastal waters }\end{array}$ & $\begin{array}{l}\text { Definition of } \\
\text { a coastal } \\
\text { "Recruit" area } \\
\text { where they } \\
\text { migrate at the } \\
\text { age of } 3 \\
\text { months. }\end{array}$ & Figure A1a & & & $\begin{array}{l}\text { Allain et al., } \\
2007\end{array}$ \\
\hline$V$ & Vital rates & & & & & \\
\hline V1 & Growth $(\mathrm{cm})$ & $\begin{array}{l}\text { Function of } \\
\text { age (monthly } \\
\text { scale) with } \\
\text { update each } \\
\text { month for } \\
\text { juveniles, } \\
\text { each year for } \\
\text { adults. }\end{array}$ & $\begin{array}{l}\text { Von Bertalanffy growth } \\
\text { function } \\
\text { Linf }=18.77 \mathrm{~cm} \\
\mathrm{~K}=1.25 \mathrm{y}^{-1} \\
\text { t0 }=-0.17 \mathrm{y}\end{array}$ & 3 & ii & $\begin{array}{l}\text { Pelgas, 2000- } \\
2005\end{array}$ \\
\hline $\mathrm{V} 2$ & Weight (kg) & $\begin{array}{l}\text { Function of } \\
\text { length for } \\
\text { adult in spring } \\
\text { and summer } \\
\text { and juveniles } \\
\text { all year. } \\
\text { Function of } \\
\text { age in autumn } \\
\text { and winter. }\end{array}$ & $\begin{array}{l}\text { age- } 1=0.018 ; \text { age }-2=0.031 ; \\
\text { age- } 3=0.04\end{array}$ & 5 & $\mathrm{i}$ & $\begin{array}{l}\text { Pelgas, 2000- } \\
2005 \\
\text { Market sampling } \\
\text { (ICES, 2000- } \\
\text { 2004) }\end{array}$ \\
\hline$M$ & Mortality & & & & & \\
\hline M1 & $\begin{array}{l}\text { Egg mortality rate } \\
\left(\text { day }^{-1}\right)\end{array}$ & & $\begin{array}{l}0.266 \text { (Megg1) } \\
0.565 \text { (Megg2) }\end{array}$ & 1 & iv & $\begin{array}{l}\text { Eggs survey, } \\
\text { Somarakis et al., } \\
2004 ; \text { ICES } \\
2006,2007 \text {, } \\
2008,2009 ; \\
\text { Pertierra, } 1997\end{array}$ \\
\hline M2 & $\begin{array}{l}\text { Adults mortality } \\
\left(\text { year }^{-1}\right)\end{array}$ & $\begin{array}{l}\text { U-shaped } \\
\text { curve: age-2 } \\
\text { mortality } \\
\text { lower than } \\
\text { age-1 and } \\
\text { age-3 }\end{array}$ & $\begin{array}{l}1.2[0.5 ; 3] \\
\text { calibrated on } 2005-2008 \\
\text { period }\end{array}$ & 3 & $\mathrm{~V}$ & $\begin{array}{l}\text { ICES, 2002- } \\
2009 ; \\
\text { Chen and } \\
\text { Watanabee, } 1989\end{array}$ \\
\hline M3 & $\begin{array}{l}\text { Juvenile mortality } \\
\left(\text { month }^{-1}\right)\end{array}$ & $\begin{array}{l}\text { Function of } \\
\text { age, monthly } \\
\text { updated for } \\
\text { juveniles } \\
\text { (until the end } \\
\text { of the first } \\
\text { reproduction) }\end{array}$ & $\begin{array}{l}\text { Exponential decay (Pareto } \\
\text { regression) between egg } \\
\text { mortality and adult } \\
\text { mortality. }\end{array}$ & 2 & ii & Lo et al., 1995 \\
\hline M4 & $\begin{array}{l}\text { Weighting factor per } \\
\text { area of the mortality } \\
\text { of larvae }\end{array}$ & $\begin{array}{l}\text { Average } \\
\text { values derived } \\
\text { from results } \\
\text { of the IBM of } \\
\text { larval drift } \\
\text { and survival }\end{array}$ & $\begin{array}{l}\text { Gironde }=0.9 ; \\
\text { Landes coastal }=1.33 ; \\
\text { Landes offshore }=0.96 ; \\
\text { Rochebonne }=0.97 ; \\
\text { North }=0.95\end{array}$ & 5 & iii & $\begin{array}{l}\text { Allain et al., } \\
2007 \text {; } \\
\text { Hinrichsen et al., } \\
2011\end{array}$ \\
\hline
\end{tabular}




\begin{tabular}{|c|c|c|c|c|c|c|}
\hline & & $\begin{array}{l}\text { through linear } \\
\text { modelling. }\end{array}$ & & & & \\
\hline $\boldsymbol{R}$ & Reproduction & & & & & \\
\hline R1 & Fecundity & $\begin{array}{l}\text { Function of } \\
\text { month and dry } \\
\text { weight }(90 \% \\
\text { of fresh } \\
\text { weight) }\end{array}$ & $\begin{array}{l}\text { Apr. }=200, \text { May }=500, \text { Jun- } \\
\text { Aug }=650\end{array}$ & 5 & ii & Motos, 1996 \\
\hline $\mathrm{R} 2$ & Spawning fraction & & Apr $=0.18$, May-Aug $=0.25$ & 5 & ii & Motos, 1996 \\
\hline R3 & Maturity & $\begin{array}{l}\text { All } \\
\text { individuals } \\
\text { mature after } \\
\text { their first } \\
\text { winter } \\
\end{array}$ & & 17 & ii & Motos, 1996 \\
\hline $\mathrm{R} 4$ & Sex ratio & & 0.5 & 1 & ii & Motos, 1996 \\
\hline R5 & $\begin{array}{l}\text { Reproduction } \\
\text { function }\end{array}$ & $\begin{array}{l}\text { Linear. } \\
\text { Biomass in } \\
\text { the last years } \\
\text { considered } \\
\text { low and } \\
\text { consequently } \\
\text { far from } \\
\text { saturation } \\
\text { threshold. }\end{array}$ & $\begin{array}{l}\text { Number of eggs }(\mathrm{t}, \text { area })= \\
\text { fecundity } \mathrm{x} \text { spawning } \\
\text { biomass }(\mathrm{t} \text {, area }) \mathrm{x} \\
\text { spawning fraction }(\mathrm{t}, \text { area })\end{array}$ & & ii & \\
\hline R6 & $\begin{array}{l}\text { Spawning timing and } \\
\text { location }\end{array}$ & $\begin{array}{l}\text { Depend on } \\
\text { area and date. }\end{array}$ & $\begin{array}{l}\text { Start mid-April in Gironde, } \\
\text { Landes coast and Landes } \\
\text { offshore; in May in } \\
\text { Rochebonne; in June in } \\
\text { North. }\end{array}$ & & ii & $\begin{array}{l}\text { Uriarte et al., } \\
\text { 1996; Allain et } \\
\text { al., } 2007\end{array}$ \\
\hline R7 & Spawning duration & $\begin{array}{l}\text { Depends on } \\
\text { individual } \\
\text { length at the } \\
\text { beginning of } \\
\text { the spawning } \\
\text { season }\end{array}$ & $\begin{array}{l}\text { Size at the time of } \\
\text { spawning depends on } \\
\text { month of birth. According } \\
\text { to the growth function, fish } \\
\text { of length } 14 \mathrm{~cm} \text { are born in } \\
\text { June. } \\
\text { R1: } \\
2 \text { months if born after June } \\
3 \text { months if born before } \\
\text { June } \\
\text { R2: } \\
2 \text { months if born after May } \\
3 \text { months if born before } \\
\text { May }\end{array}$ & 8 & ii/iv & $\begin{array}{l}\text { Pertierra et al. } \\
\text { (1997) estimated } \\
\text { spawning to last } \\
\text { for three months, } \\
\text { while Motos } \\
\text { (1996) gave a } \\
\text { duration of } 2.5 \\
\text { months and } \\
\text { differentiated } \\
\text { between fish of } \\
\text { length smaller } \\
\text { and larger than } \\
14 \mathrm{~cm} .\end{array}$ \\
\hline$A$ & Accessibility & $\begin{array}{l}\text { Probability for } \\
\text { a fish in a } \\
\text { given area at a } \\
\text { given season } \\
\text { to be fished } \\
\text { by a standard } \\
\text { fishing unit } \\
\text { with non- } \\
\text { selective gear }\end{array}$ & $\begin{array}{l}\text { Calibrated on } 2000-2004 \\
\text { period. }\end{array}$ & 3 & $\mathrm{v}$ & \\
\hline
\end{tabular}


Table A.1: Population processes integrated in the model, with modelling assumptions, parameter values, attribution to categories and references. 


\begin{tabular}{|c|c|c|c|c|c|c|c|c|c|c|c|c|c|c|}
\hline $\begin{array}{c}\text { Fleet } \\
\text { (number of } \\
\text { fishing units) }\end{array}$ & $\begin{array}{l}\text { Metier } \\
\text { targeting } \\
\text { anchovy }\end{array}$ & & Jan & Feb & Mar & Apr & May & Jun & Jul & Aug & Sep & Oct & Nov & Dec \\
\hline \multirow{8}{*}{$\begin{array}{c}\text { French pair } \\
\text { trawlers Profile } \\
1 \\
(62)\end{array}$} & \multirow{2}{*}{ Rochebonne } & prop & 0.22 & 0.08 & 0.03 & 0 & 0 & 0.33 & 0.25 & 0.15 & 0.18 & 0.09 & 0.19 & 0.03 \\
\hline & & targetF & \multicolumn{12}{|c|}{1} \\
\hline & \multirow[t]{2}{*}{ Gironde } & prop & 0.11 & 0.15 & 0.14 & 0 & 0 & 0.07 & 0.01 & 0.06 & 0.09 & 0.05 & 0.12 & 0 \\
\hline & & targetF & \multicolumn{12}{|c|}{0.98} \\
\hline & \multirow[t]{2}{*}{ Landes } & prop & 0 & 0.01 & 0 & 0 & 0 & 0.12 & 0.03 & 0 & 0 & 0 & 0 & 0 \\
\hline & & targetF & \multicolumn{12}{|c|}{1} \\
\hline & \multirow[t]{2}{*}{ North } & prop & 0.03 & 0 & 0 & 0 & 0 & 0.03 & 0.25 & 0.47 & 0.48 & 0.56 & 0.32 & 0.02 \\
\hline & & targetF & \multicolumn{12}{|c|}{0.98} \\
\hline \multirow{8}{*}{$\begin{array}{c}\text { French pair } \\
\text { trawlers Profile } \\
2 \\
(42)\end{array}$} & \multirow[t]{2}{*}{ Rochebonne } & prop & 0.02 & 0.01 & 0.01 & 0 & 0 & 0.07 & 0.03 & 0.05 & 0.02 & 0.01 & 0.01 & 0 \\
\hline & & targetF & \multicolumn{12}{|c|}{0.98} \\
\hline & \multirow[t]{2}{*}{ Gironde } & prop & 0.03 & 0.04 & 0.07 & 0 & 0 & 0.02 & 0.01 & 0.02 & 0.02 & 0.01 & 0 & 0 \\
\hline & & targetF & \multicolumn{12}{|c|}{0.96} \\
\hline & \multirow[t]{2}{*}{ Landes } & prop & 0 & 0 & 0 & 0 & 0 & 0.08 & 0.01 & 0 & 0 & 0 & 0 & 0 \\
\hline & & targetF & 0.71 & 0.42 & \multicolumn{2}{|c|}{0.71} & \multicolumn{3}{|c|}{0.99} & \multicolumn{5}{|c|}{0.71} \\
\hline & \multirow[t]{2}{*}{ North } & prop & 0.01 & 0.03 & 0.01 & 0 & 0 & 0 & 0.07 & 0.07 & 0.15 & 0.08 & 0.04 & 0 \\
\hline & & targetF & & 0.83 & & & 0.86 & & & & 0.98 & & & 0.9 \\
\hline \multirow{4}{*}{$\begin{array}{c}\text { Purse seiners } \\
\text { Basque } \\
\text { Country } \\
(9)\end{array}$} & \multirow[t]{2}{*}{ Landes } & prop & 0 & 0 & 0 & 0.7 & 0.84 & 0.59 & 0.22 & 0.12 & 0.06 & 0 & 0 & 0 \\
\hline & & targetF & & 0 & & 0.88 & 0.69 & 0.72 & 0.6 & \multicolumn{2}{|c|}{1} & \multicolumn{3}{|c|}{0} \\
\hline & \multirow[t]{2}{*}{ Gironde } & prop & 0 & 0 & 0 & 0 & 0 & 0 & 0.02 & 0.03 & 0.01 & 0 & 0 & 0 \\
\hline & & targetF & \multicolumn{6}{|c|}{0} & 0.95 & 0.75 & 0.68 & \multicolumn{3}{|c|}{0} \\
\hline & Brittany & prop & 0 & 0 & 0 & 0 & 0.03 & 0 & 0 & 0.16 & 0.5 & 0.41 & 0.2 & 0 \\
\hline Brittany & & targetF & & & & & 0.32 & & & & & & & 0.3 \\
\hline & Landes & prop & 0 & 0 & 0 & 0.19 & 0.12 & 0.02 & 0 & & & 0 & 0 & 0 \\
\hline & & targetF & & 0.64 & & & & 0.46 & & & & & & \\
\hline Spanish purse & South corner & prop & 0 & 0 & 0 & 1 & 1 & 1 & 0 & 0 & 0 & 0 & 0 & 0 \\
\hline seiners & & targetF & & 0 & & 0.43 & 0.85 & 0.44 & & & & & & \\
\hline$(222)$ & Cantabria & prop & 1 & 1 & 1 & 0 & 0 & 0 & 1 & 1 & 1 & 1 & 1 & 1 \\
\hline & & targetF & & & & & & & 0.24 & & & 0.04 & & \\
\hline $\begin{array}{c}\text { Spanish purse } \\
\text { seiners - Païta } \\
\text { (107 vessels }\end{array}$ & Gironde & & & & & & & & & $\begin{array}{c}\text { Age 1 } \\
\text { /big Age } \\
0\end{array}$ & & & & \\
\hline $\begin{array}{c}\text { harvesting } 2 \mathrm{~T} \text { each } \\
\text { every two weeks as } \\
\text { live baits) }\end{array}$ & South $46^{\circ}$ & & & & & & & & & & & & & \\
\hline
\end{tabular}

Table A.2: The table contains all parameters relative to fleets, métiers and strategies. Number of vessels in each fleet is indicated in brackets. Métiers are designated in the table according to their area of practice and characterized by a target factor (targetF) depending 
on seasons which represent the intensity of search of this métier on anchovy. Target factors are classified in category (i). The proportion (prop) of fishing time spent on each métier each month belongs to category (iii) and average values are reported. 


\begin{tabular}{|c|c|c|c|c|c|}
\hline Month & Br_PS & BC_PS & Prof1_PT & Prof2_PT & Sp_PS \\
\hline 1 & 58 & 25 & 68 & 86 & 15 \\
\hline 2 & 42 & 20 & 95 & 85 & 11 \\
\hline 3 & 26 & 19 & 121 & 83 & 129 \\
\hline 4 & 20 & 17 & 109 & 103 & 206 \\
\hline 5 & 37 & 23 & 63 & 84 & 381 \\
\hline 6 & 37 & 34 & 91 & 83 & 245 \\
\hline 7 & 68 & 41 & 81 & 73 & 84 \\
\hline 8 & 69 & 49 & 84 & 64 & 54 \\
\hline 9 & 55 & 42 & 71 & 59 & 62 \\
\hline 10 & 19 & 23 & 52 & 60 & 71 \\
\hline 11 & 26 & 19 & 48 & 73 & 84 \\
\hline 12 & 17 & 11 & 14 & 49 & 40 \\
\hline
\end{tabular}

Table A.3: Average total fishing time (hours) per boat for each fleet each month (category iii). Sp_PS: Spanish purse seiner fleet; BC_PS: Basque Country purse seiner fleet, Br_PS: Brittany purse seiner fleet, Prof1_PT: profile 1 pair trawler fleet; Prof2_PT: profile 2 pair trawler fleet 


\begin{tabular}{|l|l|l|}
\hline \multicolumn{1}{|c|}{ Gear } & Standardization factor $\left(\mathrm{SF}_{\text {std }}\right)$ & \multirow{2}{*}{ Minimum length of catch } \\
\hline French purse seine & 1 & \multirow{2}{*}{$9 \mathrm{~cm}$} \\
\hline Spanish purse seine & 0.0686 & \\
\hline Pair trawl & 0.8 & \\
\hline
\end{tabular}

Table A.4: Standardization factors of each gear (category ii) and minimum length of catch (category i). 
Figure Appendix A1a
Click here to download high resolution image

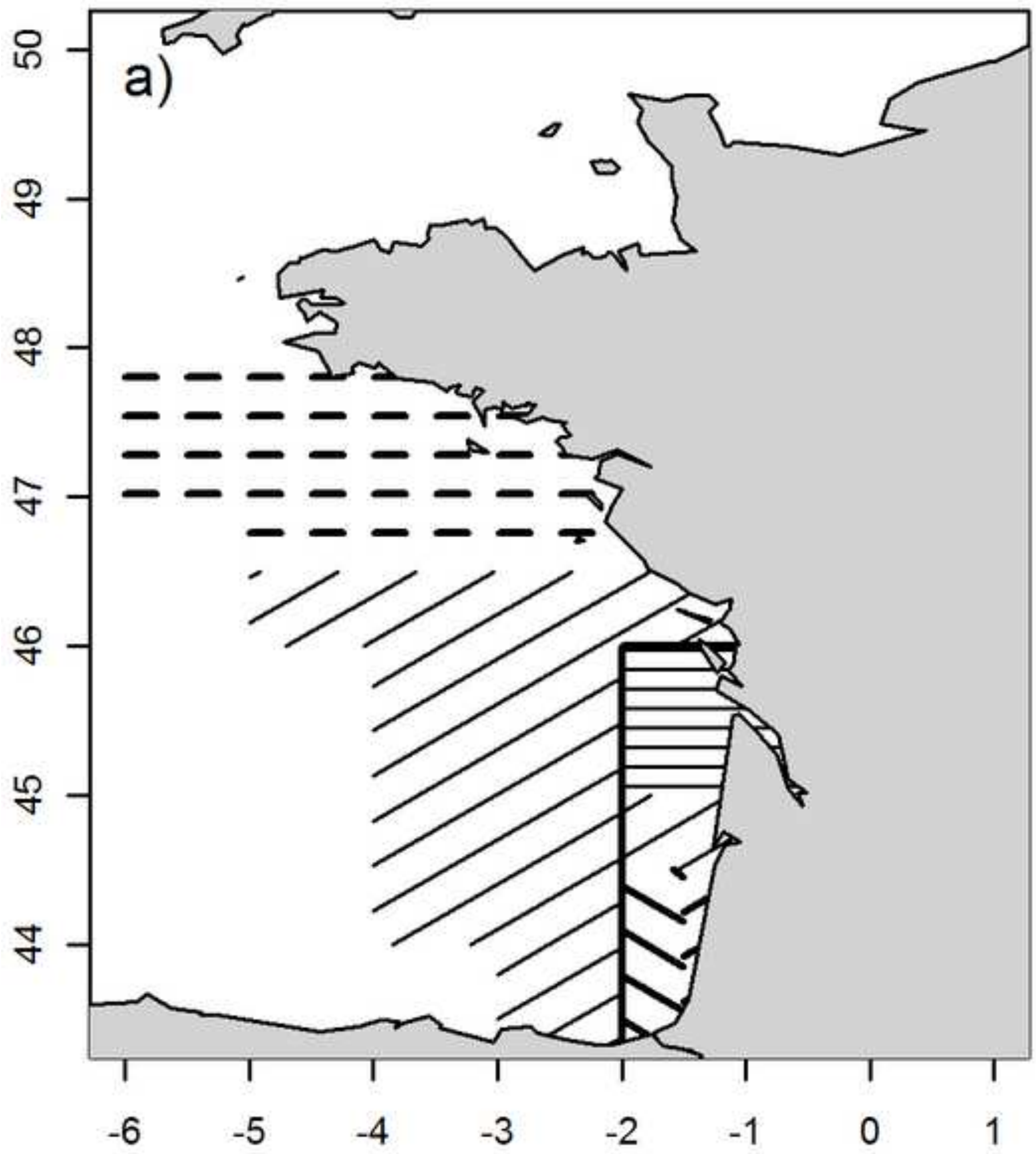


Figure Appendix A1b
Click here to download high resolution image

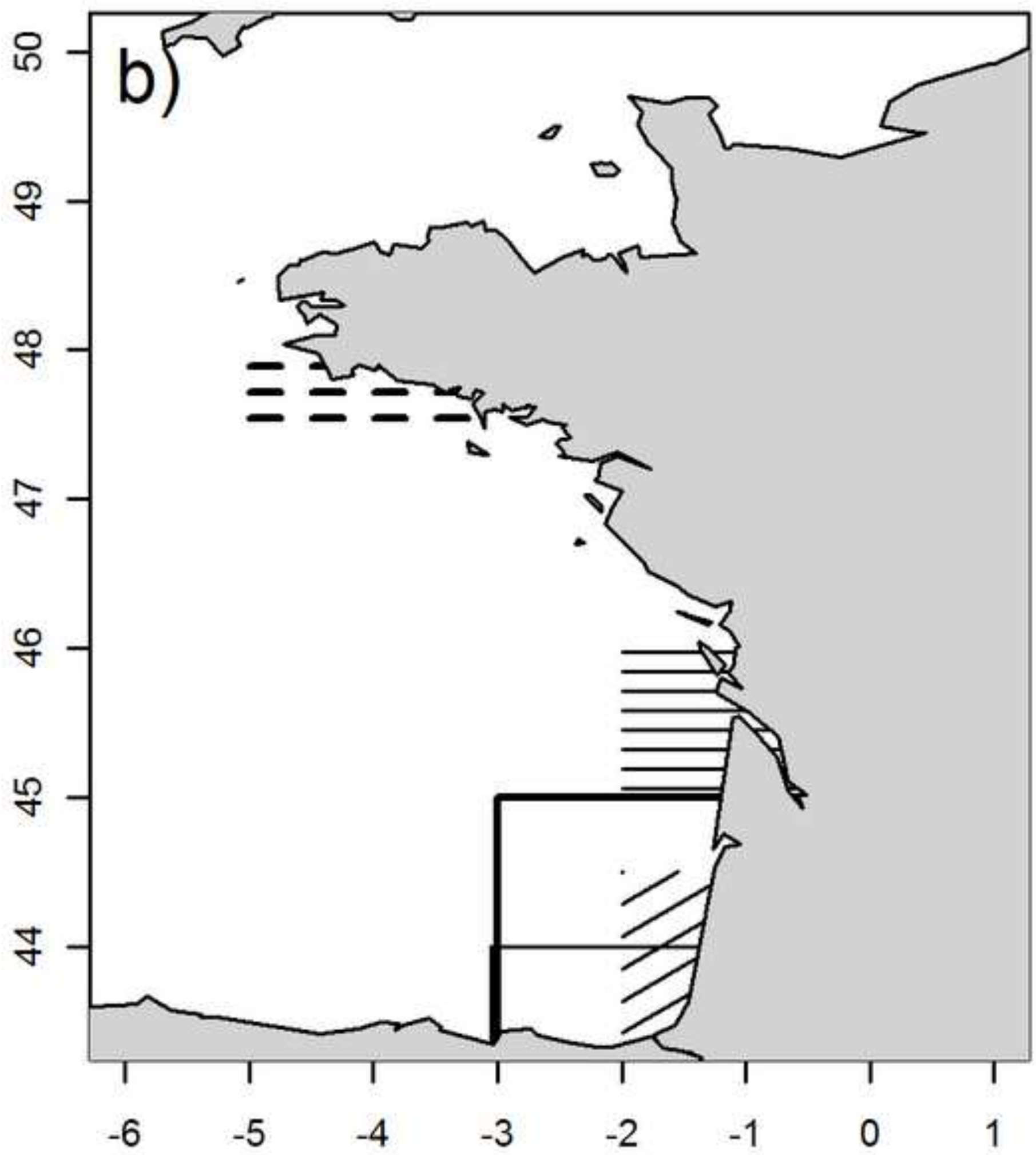


Figure Appendix A1c
Click here to download high resolution image

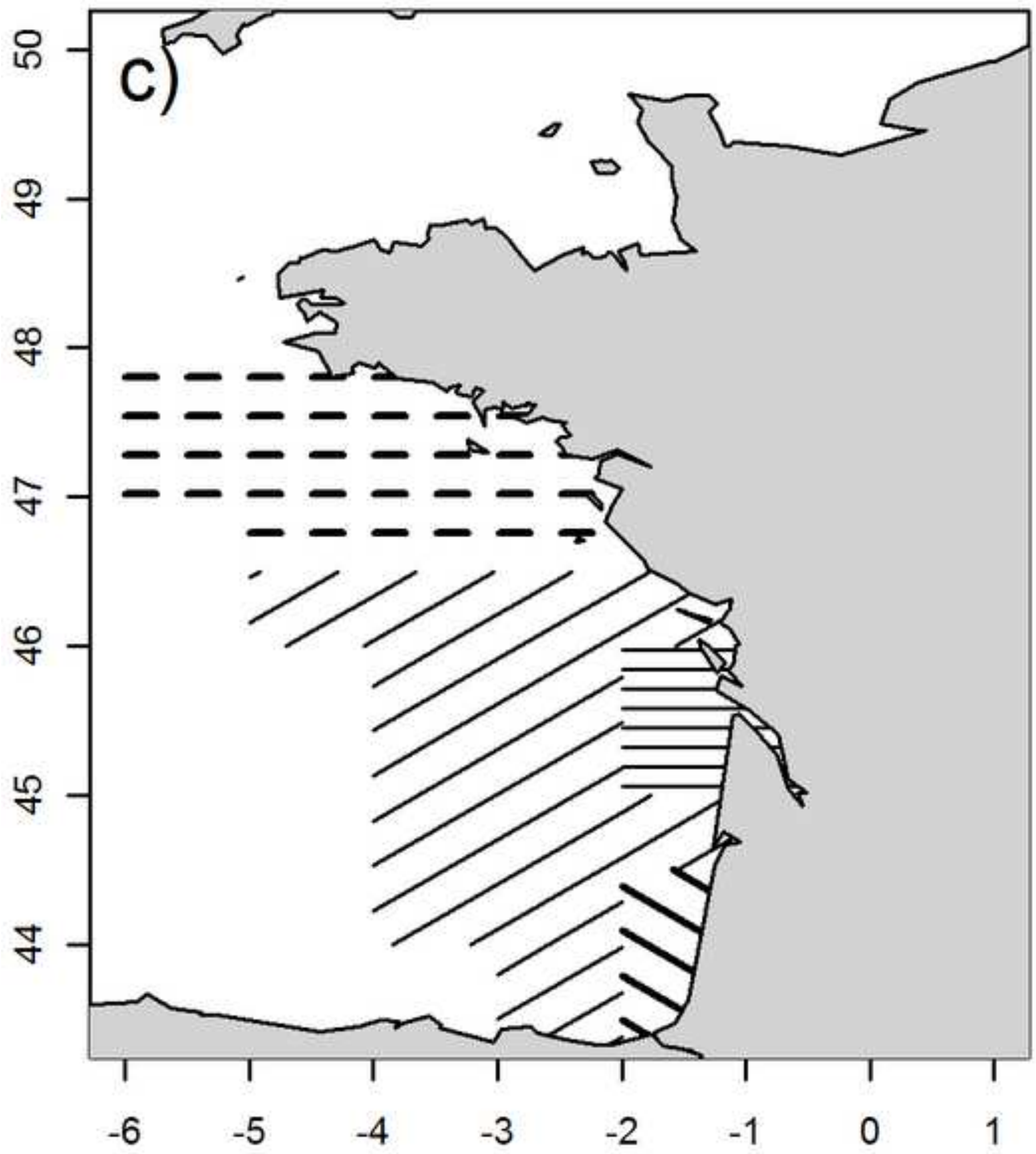


Click here to download high resolution image

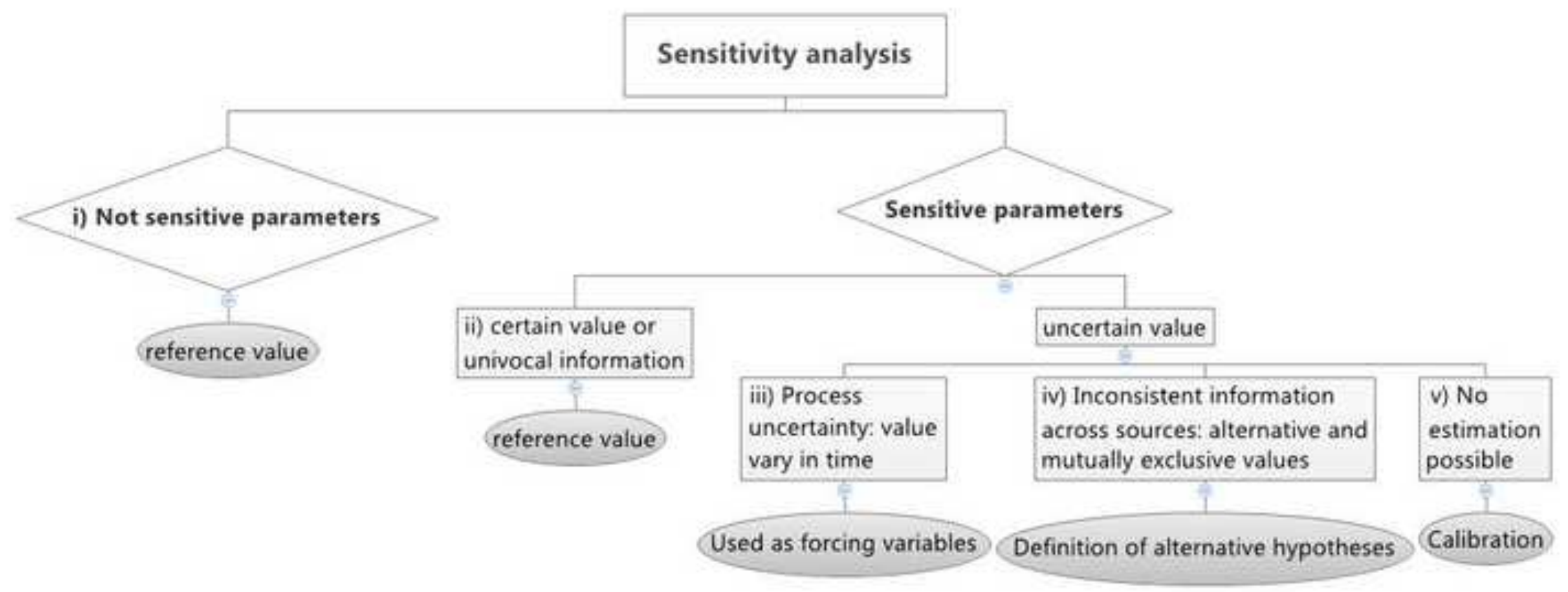



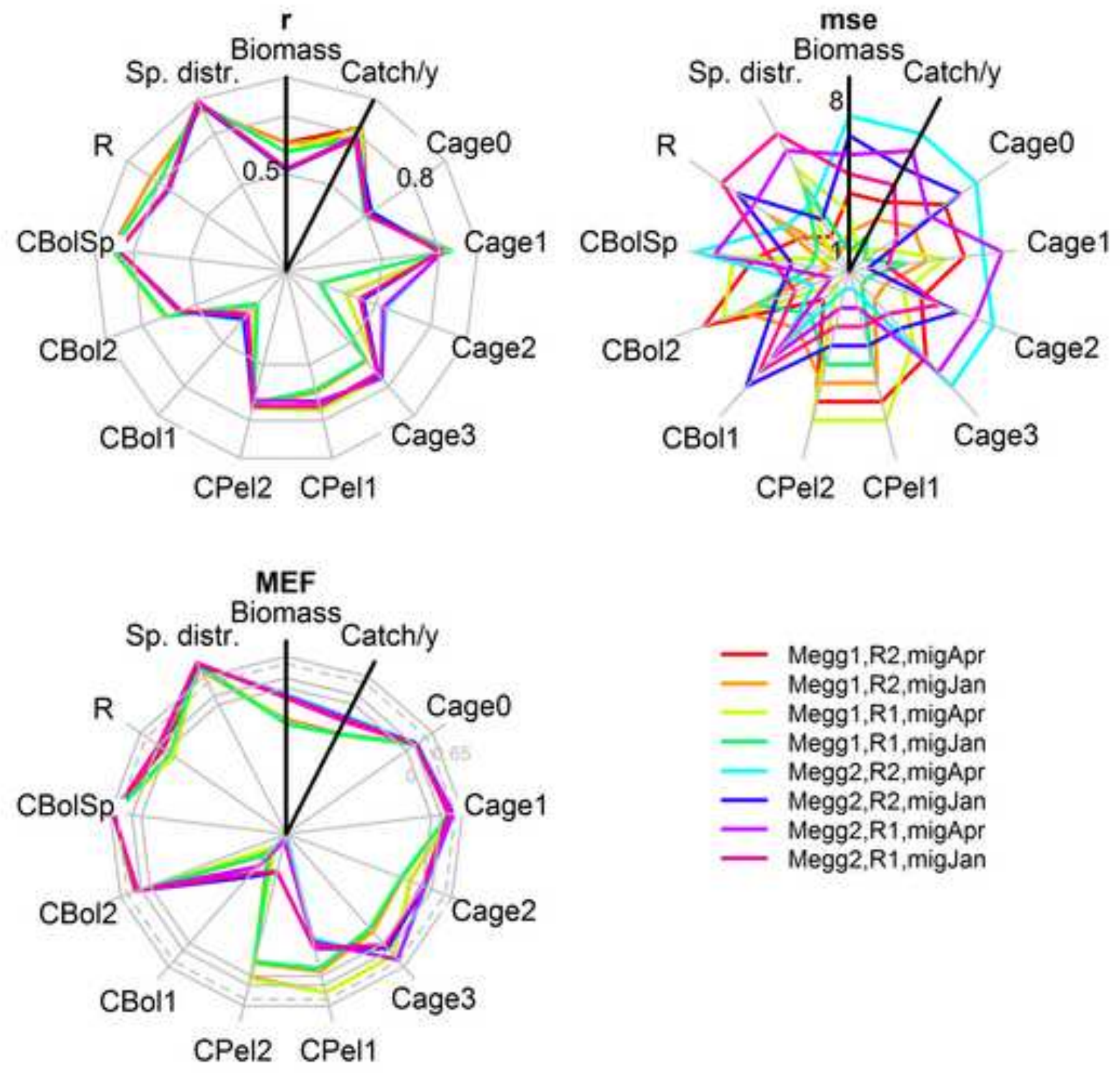

CPel2 CPel1 


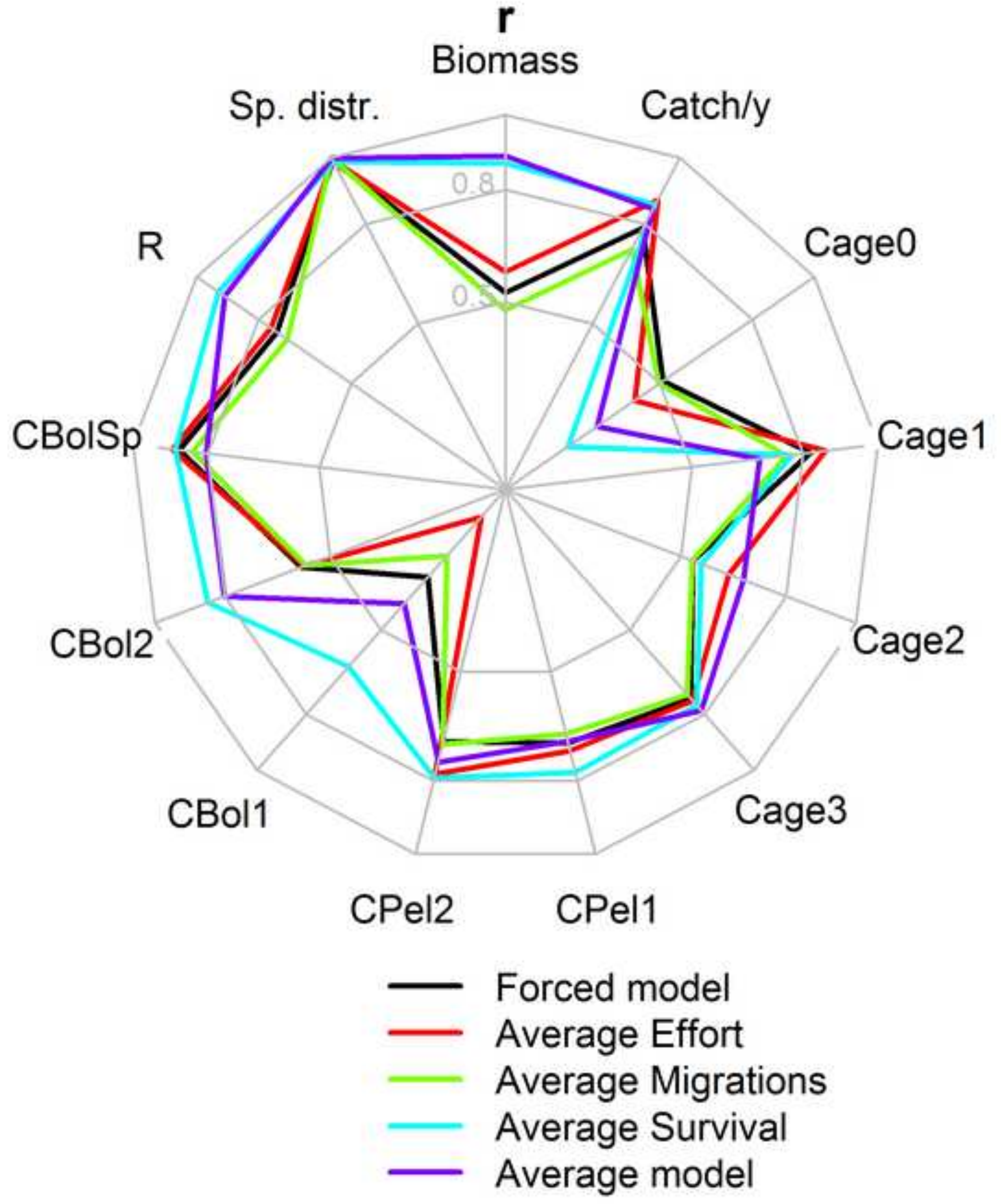




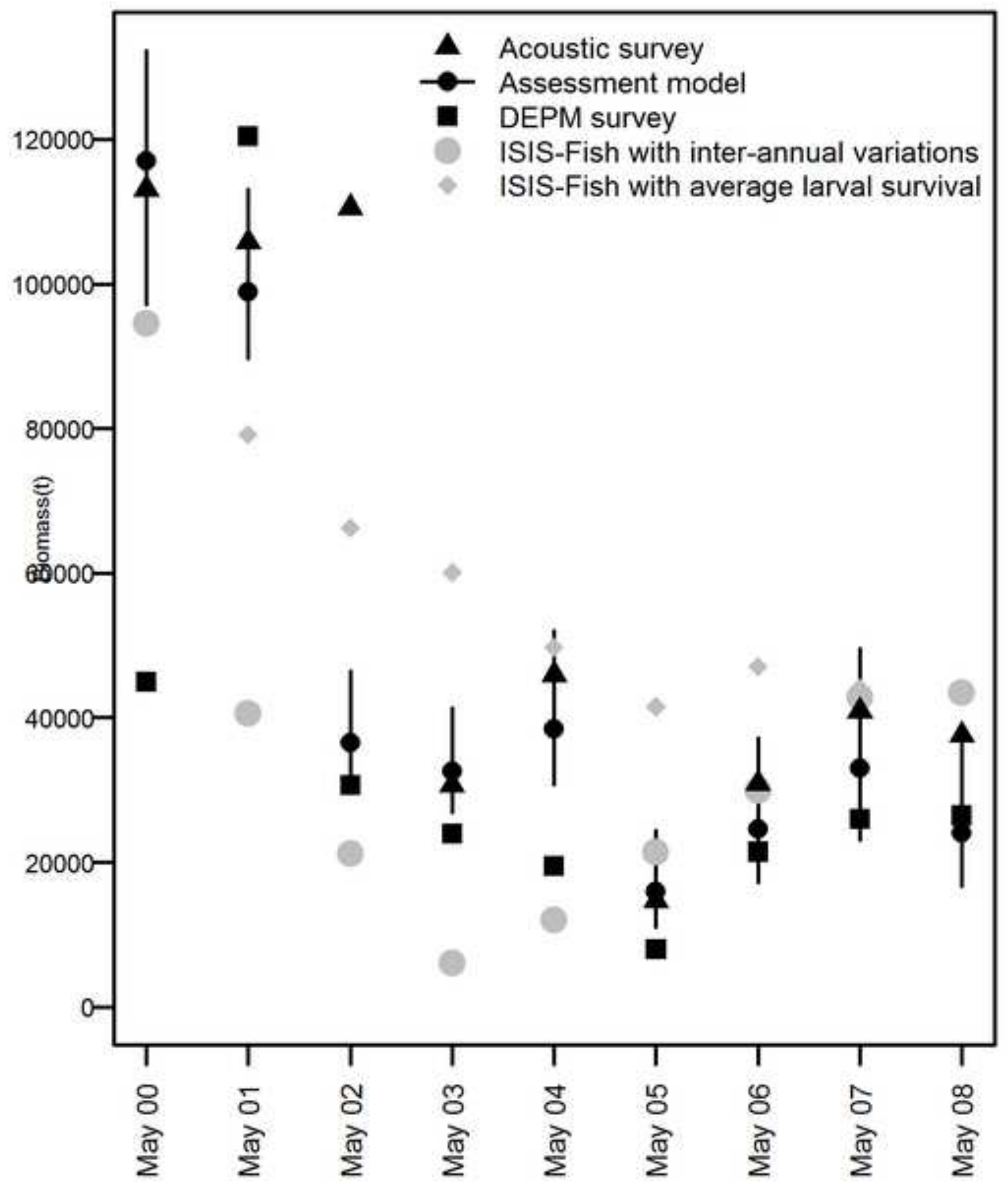


Figure 1: Parameter hierarchy: Discrimination tree to attribute parameters to categories according to their sensitivity and the level and nature of uncertainty on their value.

Figure 2: Model skill assessment: Radar plots of the scores of each alternative parameterisation (coloured lines) against each output variable (radial lines) and summary statistics with best parameterisation at the outer ends (top left: correlation value, top right: Mean squared error of the parameterisation, ranked (from 1 to 8), bottom left: model efficiency, with thin grey lines representing reference values of $\mathrm{MEF}<0.2$ : poor; $<0.5$ : good; $<0.65$ : very good; $>0.65$ excellent, Allen et al., 2007). Biomass: time series of annual stock biomass 2000-2008, Catch/y: time series of annual catches 2000-2004, Cage0 (resp. Cage1, Cage2, Cage3): time series of the catches at age 0 per quarter (resp. age 1, age 2, age $3+$ ), CPel1 (resp. CPel2, CBol1, CBol2, CBolSp): time series of monthly catches by French pair trawler profile 12000 -2004 (resp. French pair trawlers profile 2, French purse seiners profile 1, French purse seiners profile 2, Spanish purse seiners), R: time series of annual recruitment biomass, Sp. distr.: average distribution of egg production per month over the spawning season. See text for details on statistics.

Figure 3: Forcing variables impact on correlation: The radar plot displays the correlation between observations and predictions (best at the outer end) for each simulation (coloured lines) and each output variable (radial lines). Simulations are run with all forcing variables (forced model), or with one forcing relaxed (average effort, average mortality, average migration) or with all forcing variables averaged (average model).

Figure 4: Time series of population biomass in May (2000-2008) as derived from the acoustic surveys, DEPM surveys, ICES assessment of anchovy (Assessment model) (in black) and hind-casted by ISIS-Fish with forced with larval mortality, spatial distribution and fishing effort (grey dots) or without the forcing by early survival (grey diamonds).

Appendix figures:

Figure A1: Maps of the fishery region. a) Populations areas for anchovy: wintering area (horizontal dashed lines); spawning areas: Gironde (horizontal lines), Rochebonne (upward hatched lines), Landes coast (bold upward hatched lines), Landes offshore (bold downward hatched lines); recruitment area (box). b) Purse seiners areas of practice: French fleets: Brittany (horizontal dashed lines), Gironde (horizontal lines), Landes (upward lines); Spanish fleets: South corner (thin line box), Cantabria (bold box). c) French pair trawlers areas of practice: North (horizontal dashed lines), Rochebonne (upward lines), Gironde (horizontal lines), Landes (downward bold lines). 